\title{
PECVD application to obtain polymer coated graphene nanoplatelets and development of new epoxy nanocomposites
}

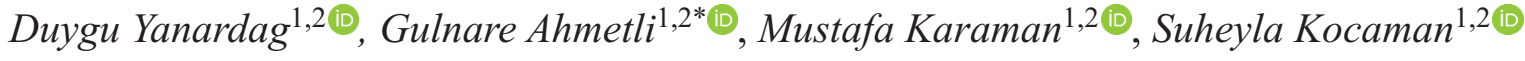 \\ ${ }^{1}$ Department of Chemical Engineering, Faculty of Engineering and Natural Sciences, Konya Technical University, 42022 , \\ Campus, Konya, Turkey \\ ${ }^{2}$ Department of Chemical Engineering, Faculty of Engineering, Selcuk University, 42022, Campus, Konya, Turkey
}

Received 3 June 2021; accepted in revised form 5 August 2021

\begin{abstract}
In this study, graphene nanoplatelets (GNPs) were synthesized from graphite by a liquid-phase exfoliation (layer separation) method, and their surfaces were functionalized with poly(glycidyl methacrylate) (PGMA) by using the rotatingbed plasma-enhanced chemical vapor deposition (PECVD) method. Fourier-transform infrared spectroscopy (FT-IR), Raman spectroscopy, scanning electron microscopy (SEM), X-ray powder diffraction (XRD), and thermogravimetric (TGA) analyses were performed to characterize the unmodified (u-GNP) and modified GNP (PGMA-GNP). Epoxy nanocomposites were prepared with both types of GNPs at different loading levels $(0.1-2 \%$ by weight). The role of the surface modification of the GNPs on the mechanical, thermal, electrical conductivity, contact angle, water sorption, and corrosion properties of the epoxy nanocomposite coatings was also investigated. Consequently, the tensile strength and Young's modulus of the epoxy resin (ER)/PGMA-GNP nanocomposites were enhanced by $10.2-20$ and 3.3-18.4\%, respectively, as compared to the ER/u-GNP composites. Moreover, the nanocomposites prepared with PGMA-GNP had better water sorption and wettability properties than those prepared with u-GNP, but lower electrical conductivity. The corrosion test results showed that the addition of GNPs to epoxy effectively improved the corrosion resistance of the epoxy composites in high salinity, basic, and acidic environments.
\end{abstract}

Keywords: nanocomposites, graphene nanoplatelets, PECVD, surface modification, epoxy

\section{Introduction}

Epoxy resins (ERs) are widely used thermosets owing to their wide range of applications. They possess noteworthy features, such as good electrical and mechanical properties, thermal stability, solvent and chemical resistance, humidity resistance, and excellent adhesive features for many coating applications $[1,2]$. Despite their many superior properties, epoxides have some drawbacks, such as low impact resistance, high brittleness, and low thermal and electrical conductivities, which limit their application when used without any reinforcement. To overcome these undesirable effects, compatible fillers such as graphene [1], nanosilica [2], carbon nanotubes [3], and nanoclay [4] are incorporated into the epoxy. Although there are challenges, polymer nanocomposites are applied in the coating industry, and studies show that their commercial impact will significantly increase in the future.

Graphene nanoplatelets (GNPs) are formed by combining several layers of graphene sheets. Like other carbon-based developments, it is of great interest in many areas due to its excellent mechanical, thermal, and electrical properties. Moreover, it is hydrophobic and environmentally friendly [5]. The superior properties of GNPs have enabled their use in recent years 
as high-efficiency fillers to produce polymer composites and coatings with improved properties [1]. Nanocomposites containing small amounts of GNPs exhibit superior properties such as mechanical, thermal, gas barrier, electrical conductivity, and anticorrosion, to that of pure polymers [6-8].

The enhancement of the composite properties strongly depends on the level of dispersion of the GNPs in the polymer matrix. Because pristine GNPs tend to aggregate during the mixing process due to Van der Waals forces, the uniform dispersion of the GNPs in the matrix during the production of such composites is very important for achieving the final composite properties [9]. The agglomeration of filler particles in epoxy also affects the final product properties; however, modifying the surface of nanoplatelets can enhance the compatibility between the filler and the polymer and provide desirable final product properties.

Various studies have been conducted to increase the dispersion of nanofillers in polymers, including ultrasonication and physical or chemical modifications [10]. Better distribution and compatibility between the filler and matrix can be achieved by surface modification of the GNPs. Functionalization of the graphene surface increases the dispersion and the interaction between GNPs and the polymer matrix [11]. Another advantage of using functional graphene is the creation of hydrogen-bonding networks, which can greatly increase interfacial bonding between functional groups and the polar polymer chains. The surface properties of graphene can be chemically modified for specific purposes by using different modifying agents, such as ionic liquids [12], (3-glycidyloxypropyl) trimethoxysilane [13], and functional carboxyl (-COOH) groups [14]. Polymeric surface modification is an easy way to alter graphene nanomaterials to achieve the desired surface properties. Polymer surface modification is an effective way to create stable graphene dispersions to avoid agglomeration owing to its high surface energy. For the surface modification or coating of GNPs with polymers, various techniques, such as oxidation polymerization [15], plasma-based chemical functionalization [16], chemical modification [17], and grafting by radical polymerization [18], have been used. Coating the surfaces of nano-additives is very attractive owing to their ability to form a coating layer on the material with special properties, its homogeneity, and the ability to impart a new performance to a material. Quiles-Díaz et al. [19] reported that the covalent functionalization of graphene with polymers enabled the homogeneous dispersion of graphene, the adequate control of the microstructure of the nanocomposites, and prevented the restacking of the graphitic sheets.

Compared to chemical methods, plasma-enhanced chemical vapor deposition (PECVD) is an all-dry and single-step method that does not require an organic solvent. Coating polymers by plasma is a versatile method for implementing ultrathin polymeric layers on a wide range of materials. PECVD, which is different from other chemical vapor deposition (CVD) processes, activates the chemical reaction of precursors with plasma and requires a lower temperature than conventional CVD. Plasma modification can alter material surface properties, such as hydrophilicity, conductivity, biocompatibility, surface energy, and adhesion [3]. Recently, Kocaman [20] used poly(acrylic acid)-coated coconut waste using the PECVD method as an adsorbent for the removal of methylene blue dye.

No literature on the PECVD polymer coating of GNPs is available. Additionally, the use of polymercoated nanofillers by PECVD in a composite preparation was performed for the first time by the authors $[3,21]$, and no other studies have been conducted on this topic by other researchers. As a continuation of these studies, this novel study coated GNP surfaces with poly(glycidyl methacrylate) (PGMA) as a filler in epoxy nanocomposites by the rotating-bed PECVD method. The glycidyl methacrylate (GMA) monomer was chosen because it may serve as a good compatible agent because of the epoxy groups that it possesses. While coating of the GNP surfaces is very limited when the particle bed is stationary, the particles coated with the rotating-bed PECVD method are equally exposed to plasma owing to continuous agitation. Additionally, ample studies on the use of GNPs in ER exist and they generally investigated the electrical and thermal conductivity, storage, flexural modulus, and fracture toughness [9, 22-24]. To determine the anticorrosive performance, Ding et al. [25] studied the water sorption, and contact angle (CA) of a hydroxyl epoxy phosphate monomer enhanced graphene/epoxy coating. However, the nanocomposite coating properties, their mechanical behavior, thermal stability, water sorption, surface wettability, corrosion, and electrical conductivity were comparatively examined for the first time in this study. 


\section{Materials and methods}

\subsection{Materials}

Pristine graphite powder was supplied from Graphit Kropfmühl AMG (Hauzenberg/Germany) and was suspended in an ethanol solution with a stirrer for high purity once it was received. $N, N$-dimethylformamide (DMF), epoxy embedding medium accelerator 2,4,6-tris(dimethyl aminomethyl)phenol, GMA, and ethanol were purchased from Sigma-Aldrich Ltd. (USA). Bisphenol A-type ER (NPEK 114) was supplied by Konuray Chemical Co. (Turkey). The hardener, commercially known as Docure KH-816 (a cycloaliphatic amine), was purchased from Sar Chemical Co. (Turkey).

\subsection{Liquid-phase exfoliation of graphite}

Graphene was produced from graphite using the liquid-phase exfoliation (layer separation) method.

Graphite $(1.0 \mathrm{~g})$ and DMF $(300 \mathrm{ml})$ were mixed in a beaker, and the mixture was subjected to magnetic stirring and probe sonication (SONOPULS, Ultrasonic Homogenizer, Model UW 3200, 200 W) at $20 \%$ power for $6 \mathrm{~h}$. The beaker was placed in an ice container to prevent the heating of the mixture. After sonication, the dark dispersion mixture was centrifuged at $4000 \mathrm{rpm}$ for $10 \mathrm{~min}$ to remove large particles, and homogeneous mixtures of GNPs and DMF were obtained. The final dispersion was centrifuged at $9000 \mathrm{rpm}$ for $45 \mathrm{~min}$ to obtain GNPs (Figure 1).

\subsection{Surface modification of GNP by PECVD} The polymerization of GMA on GNPs was performed using a rotating-bed PECVD system. In this system, a cylindrical Pyrex tube $(7 \mathrm{~cm}$ outer diameter, $50 \mathrm{~cm}$ length) was used as the vacuum reactor. The DC motor was connected to a vacuum chamber to provide rotation, and the particles were continuously exposed to plasma. The rotation speed of the reactor was adjusted to $12 \mathrm{rpm}$. The GMA monomer was held in a stainless-steel jar, and the temperature was controlled using heating tape wrapped around the jar. The monomer temperature was set to $55^{\circ} \mathrm{C}$ using a proportional-integral-derivative (PID) temperature controller. Through experimentation, the reactor pressure was maintained at 300 mTorr, which was measured by a capacitance-type pressure gauge (MKS, Baratron), and the surface was exposed to a $40 \mathrm{~W}$ plasma power for $20 \mathrm{~min}$. To evaluate the coating thickness and characterization, a silicon wafer (100, p-type) was placed in a vacuum chamber (Figure 1).

\subsection{Composite preparation}

Two different types of composites were prepared with unmodified (u-GNP) and modified GNPs (PGMA-GNP). A small amount of graphene can significantly improve the mechanical, electrical, and thermal properties of polymer composite materials [26]. Therefore, GNPs were dispersed into the epoxy matrix in $0.1,0.3,0.5,1.5$, and $2.0 \mathrm{wt} \%$ by using a mechanical stirrer and ultrasonic bath at $60^{\circ} \mathrm{C}$ for

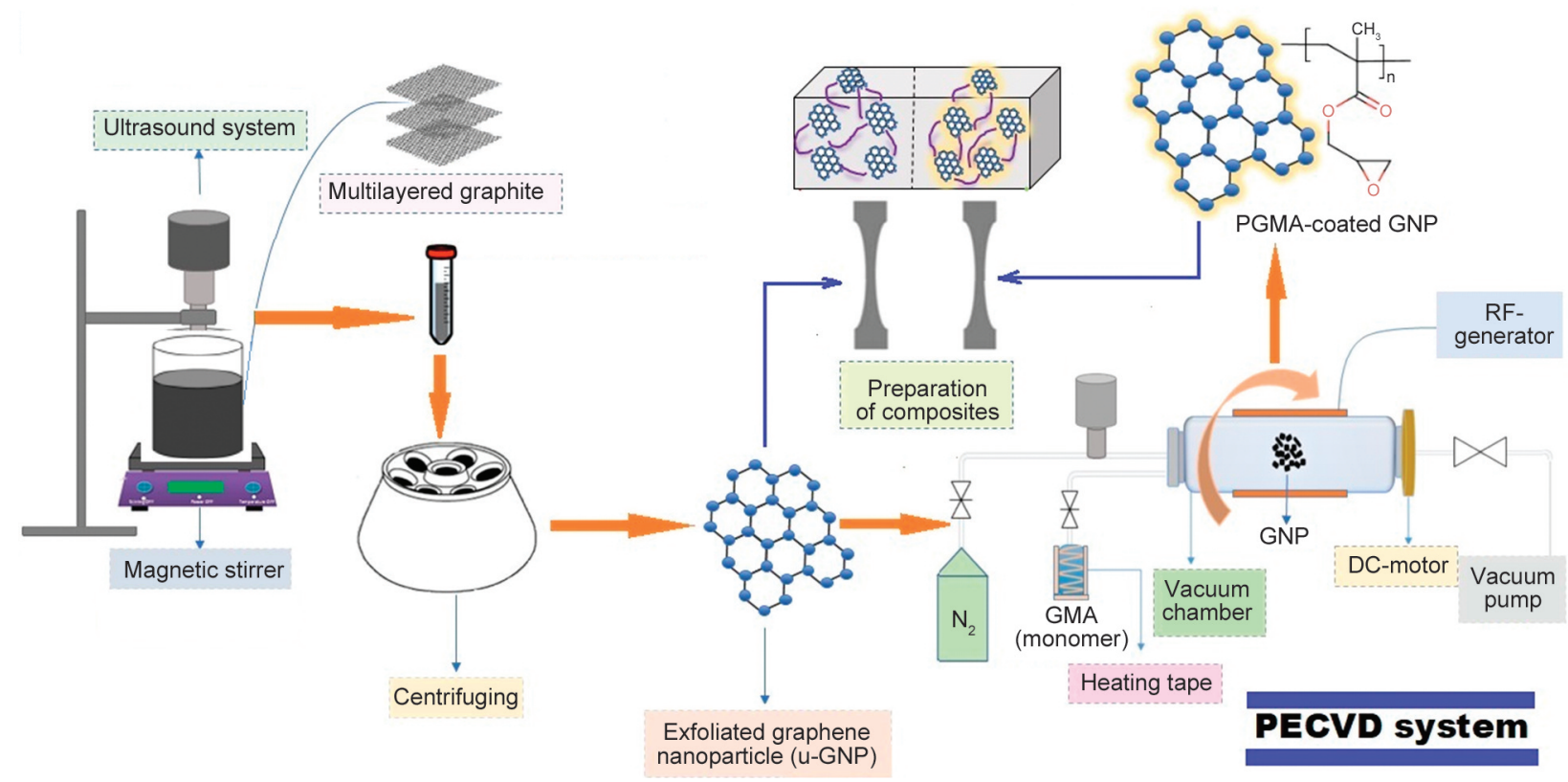

Figure 1. Schematic presentation of synthesis and PECVD coating of GNP which used in the composite preparation. 
$1 \mathrm{~h}$. After dispersion, the curing agent $(30 \mathrm{wt} \%)$ and accelerator $(1.0 \mathrm{wt} \%)$ were added. The mixture was poured into a stainless-steel mold that was prepared according to the ASTM D 638 standard for the forming process $[27,28]$ (Figure 1). Curing was conducted at $40^{\circ} \mathrm{C}$ and post-curing at $80^{\circ} \mathrm{C}$ for $24 \mathrm{~h}$ at each temperature.

\subsection{Characterization}

Raman analysis (Renishaw inVia Reflex confocal Raman microscope) was used to examine the structural characteristics of the as-produced GNPs. Fourier-transform infrared spectroscopy (FT-IR; Bruker Vertex 70) was employed to reveal the chemical structure of the PECVD-coated thin film (PGMA) and characterize the synthesized GNPs. FT-IR spectra were recorded in the wavenumber range of 3600 $600 \mathrm{~cm}^{-1}$ at a resolution of $4 \mathrm{~cm}^{-1}$ and averaged over a total of 32 scans. Transmission electron microscopy (TEM; JEOL JEM-2100) at an acceleration voltage of $200 \mathrm{kV}$ was used to visualize the morphologies of the pure and PGMA-coated GNPs. The morphology of the composites was characterized by scanning electron microscopy (SEM; Zeiss EVO LS10 electron microscope with a Bruker $123 \mathrm{eV}$ EDX sensor). Static CA measurements were performed at 10 different points on the samples using a CA goniometer (Kruss Easy Drop) with $2.0 \mu 1$ of deionized water.

$\mathrm{X}$-ray diffraction (XRD) was conducted on a Bruker $\mathrm{D} 8$ Advance powder diffractometer with $\mathrm{Cu}-\mathrm{K} \alpha$ radiation $(\lambda=1.5406 \AA$, power $=40 \mathrm{kV})$ from $20-80^{\circ}$. The thermal analyses were performed using a Mettler Toledo thermogravimetric analyzer. Samples (approximately $10 \mathrm{mg}$ ) were heated from 50 to $800^{\circ} \mathrm{C}$ at a heating rate of $10^{\circ} \mathrm{C} \cdot \mathrm{min}^{-1}$ under a nitrogen atmosphere during the analyses. Tensile tests were performed using a Stretch and Pressing Equipment TSTMares/TS-mxe (following the ASTM D 638 standard). Hardness tests were conducted with a Shore Durometer TH 210 according to the ASTM D 2240 Standard. Three to five samples of each composite material were tested to obtain reliable values for the tensile and hardness tests.

The samples were maintained in deionized water for $26 \mathrm{~d}$ at room temperature to determine the water sorption by the gravimetric method. The samples were weighed daily after removal from the water and surface drying. The water sorption of the composites was calculated using the Equation (1):
Sorption $[\%]=\frac{W_{\mathrm{t}}-W_{0}}{W_{0}} \cdot 100$

where $W_{\mathrm{t}}$ is the mass of the sample at the corresponding time and $W_{0}$ is the mass of the dry sample.

ER/PGMA-GNP composites ( 0.3 and $1.5 \mathrm{wt} \%$ ) were exposed to $10 \% \mathrm{NaCl}, 10 \% \mathrm{NaOH}$, and $10 \% \mathrm{H}_{2} \mathrm{SO}_{4}$ for $15 \mathrm{~d}$. After removing the composites from the process solutions, the number of defects (color changes, swelling, turbidity, and others) were observed with SEM and microscopic images were taken as a measure of the corrosion resistance.

\section{Results and discussion}

\subsection{Characterization of synthesized GNP}

\subsubsection{Raman and FT-IR analyses}

The peaks at 1582 and $2700 \mathrm{~cm}^{-1}$ (Figure 2a) are characteristic peaks in the Raman spectrum of graphene and are called the $\mathrm{G}$ and 2D bands, respectively. The $\mathrm{G}$ peak is caused by the in-plane vibration of the $\mathrm{sp}^{2}$ carbon atoms, and the 2D peak, the secondorder overtone of $\mathrm{D}$, originates from a two-phonon lattice vibrational process. In the Raman spectra, the three bands of G, D, and 2D represent the $\mathrm{sp}^{2}$ carbon atoms of the graphene structure, and the graphene layer thickness can be calculated by using these bands $[29,30]$. The intensity ratio of the $2 \mathrm{D}$ and $\mathrm{G}$ bands $\left(I_{2 \mathrm{D}} / I_{\mathrm{G}}\right)$ was calculated to be 0.520 , indicating that the average number of layers of graphene plates should be less than 5 [31]. Additionally, the peak at $1350 \mathrm{~cm}^{-1}$, the D peak, is known as the defect band or disorder band. A high-intensity D band implies many defects in the material $[13,31]$. The ratio of the $\mathrm{D}$ and $\mathrm{G}$ bands $\left(I_{\mathrm{D}} / I_{\mathrm{G}}\right)$ for the synthesized graphene (u-GNP) was 0.19 , which was attributed to the small defects and high quality of the obtained GNPs [32]. The Raman spectra of the PGMA-coated GNPs showed the same D, G, and 2D bands without shifting but with $\mathrm{D}$ intensities different from those of $\mathrm{u}-$ GNP. $I_{\mathrm{D}} / I_{\mathrm{G}}$ for the PGMA-GNP was found to be 0.23 , which was slightly higher. An increase in $I_{\mathrm{D}} / I_{\mathrm{G}}$ relative to that found for u-GNP indicated that polymer chains successfully covered the surface because they were detected as defects in the carbon network by Raman spectroscopy. Vallés et al. [11] also reported that $I_{\mathrm{D}} / I_{\mathrm{G}}$ was higher for PMMA-grafted GNPs than for $\mathrm{NH}_{2}$-GNPs, possibly because of the inclusion of some additional functional groups or polymer chains physically adsorbed on the surface of the defects and/or flakes. 

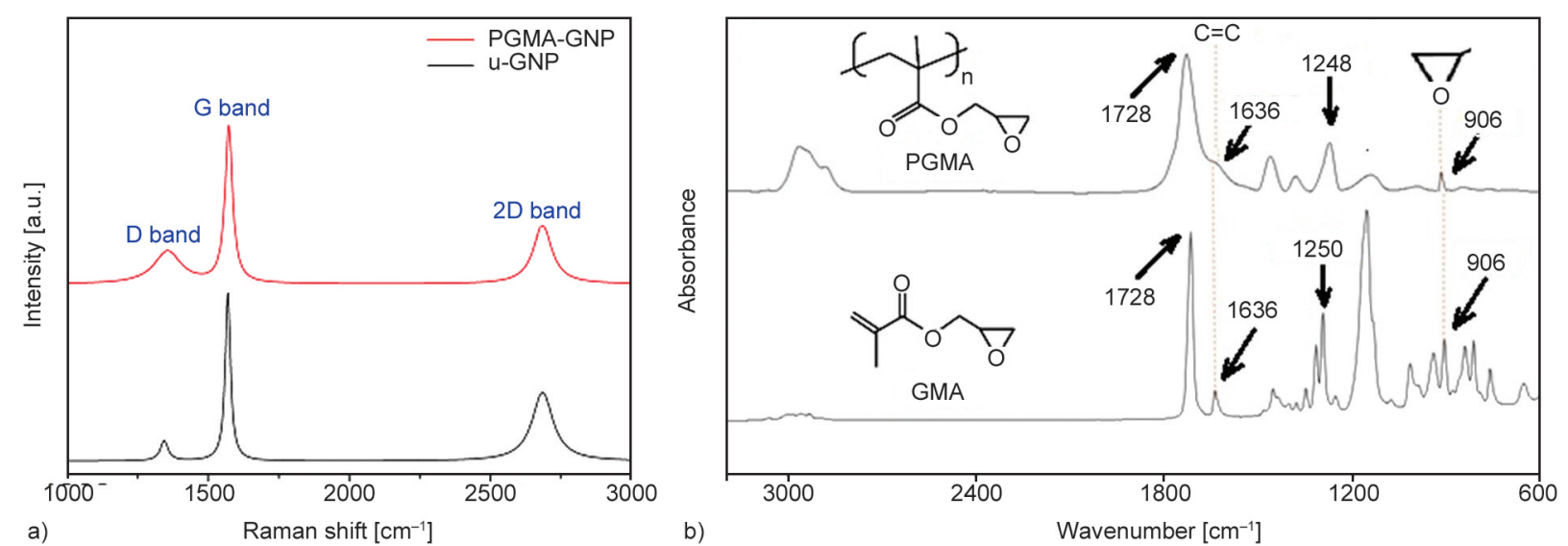

Figure 2. a) Raman spectra of u-GNP and PGMA-GNP; b) FT-IR spectra of GMA and PGMA.

The precise chemical structure of plasma-polymerized GMA is difficult to determine because plasma polymerization is a significantly more complex process than conventional polymerization. The chemical structure of GMA contains an epoxy-functional group and an unsaturated carbon-carbon $(\mathrm{C}=\mathrm{C})$ bond. The epoxy group of GMA can effectively enhance the adhesion for charge transfer and chemical bonding at the interface. GMA has been found to protect the epoxy groups during plasma polymerization and deposition on different surfaces [33]. FT-IR analysis was used to determine the possible chemical structure of the PGMA thin film. Because it is important to maintain an adequate amount of epoxy functional groups, the presence of this group in the FT-IR spectrum is desirable. Figure $2 b$ shows the FT-IR spectra of the GMA monomer and PGMA on the silicon substrate. The absorption bands at 30402800,1728 , and $1500-1400 \mathrm{~cm}^{-1}$ were assigned to $\mathrm{C}-\mathrm{H}$ stretching, $\mathrm{C}=\mathrm{O}$ stretching, and $\mathrm{C}-\mathrm{H}$ bending, respectively. The stretching vibration of the ester $\mathrm{C}-\mathrm{O}$ bond was observed at 1248 and $1250 \mathrm{~cm}^{-1}$, while the 906 and $844 \mathrm{~cm}^{-1}$ wavelengths were related to the asymmetric stretching vibration of the epoxy $\mathrm{C}-\mathrm{O}$ bond. These peaks were preserved after the polymerization of GMA. It was clear from the PGMA thinfilm spectrum that the unconjugated $\mathrm{C}=\mathrm{C}$ double bond at $1636 \mathrm{~cm}^{-1}$ disappeared. This shows that the plasma polymerization of GMA proceeds through $\mathrm{C}=\mathrm{C}$ double bonds and not the epoxide functional groups. The absorption bands at 2937, 2858, and $1450 \mathrm{~cm}^{-1}$ (the sharp alkane stretching bands) confirmed the long-chain hydrophobic end group in the polymer [34].

A rotary-bed PECVD system was used to cover the GNP surfaces as completely as possible. The coating thickness depended on the ambient conditions. The conditions under which the graphene nanoparticles would be coated were determined by coating a $\mathrm{Si}$ wafer with PGMA under different conditions. Because the highest coating speed was obtained at $40 \mathrm{~W}$ and $20 \mathrm{~min}$, according to a profilometer analysis, the GNPs were coated with PGMA under these conditions. The thickness of the coating was determined to be $811 \mathrm{~nm}$. Additionally, the PGMA polymer is thought to be physically adsorbed by the GNP surface and not covalently bonded because graphene consists only of benzene rings and does not contain groups to react with PGMA [3].

\subsubsection{SEM and XRD}

Figure 3 shows the SEM analysis results of GNPs at various magnifications. The difference in the SEM images of the u-GNP (Figure 3a) and PGMA-GNP (Figure $3 b$ ) showed that the GNPs were coated with the PGMA polymer. To achieve maximum performance, optimum adhesion between the filler and the polymer matrix is required. It was observed that the gaps between the graphene particles decreased as a result of coating with PGMA, and a tighter, more adherent image was obtained. Therefore, it was concluded that the PGMA coating occurred only on the outer surface of the GNPs, and the coating proceeded well with PECVD polymerization.

The structural properties of the GNPs were characterized by XRD analysis. Figure 4a shows the characteristic XRD patterns of $\mathrm{u}-\mathrm{GNP}$ and PGMA-GNP. The characteristic $2 \theta$ angle of the GNPs was $26.6^{\circ}$, corresponding to the (002) crystallographic plane of the graphitic structure. Additionally, the small peaks at a $2 \theta$ of 42,45 , and $55^{\circ}$ corresponded to the (100), (101), and (004) crystallographic planes, respectively 


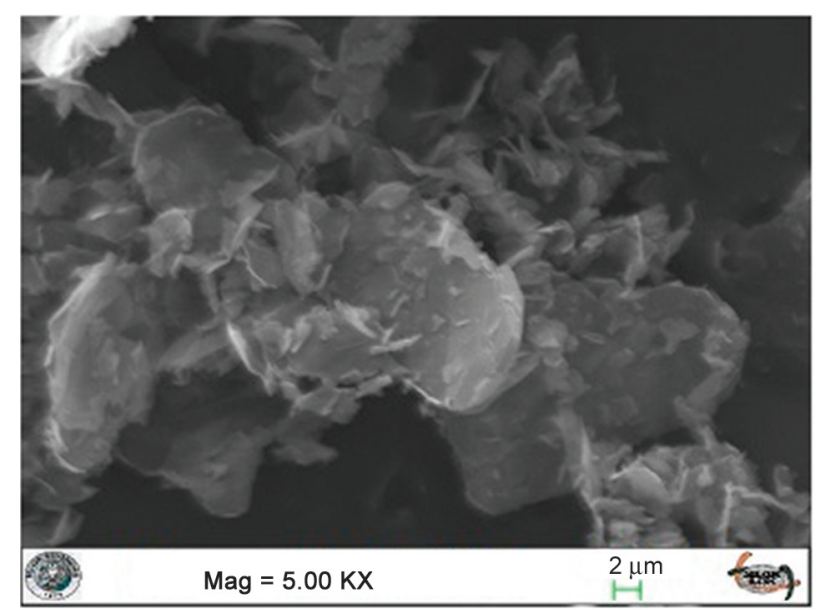

a)

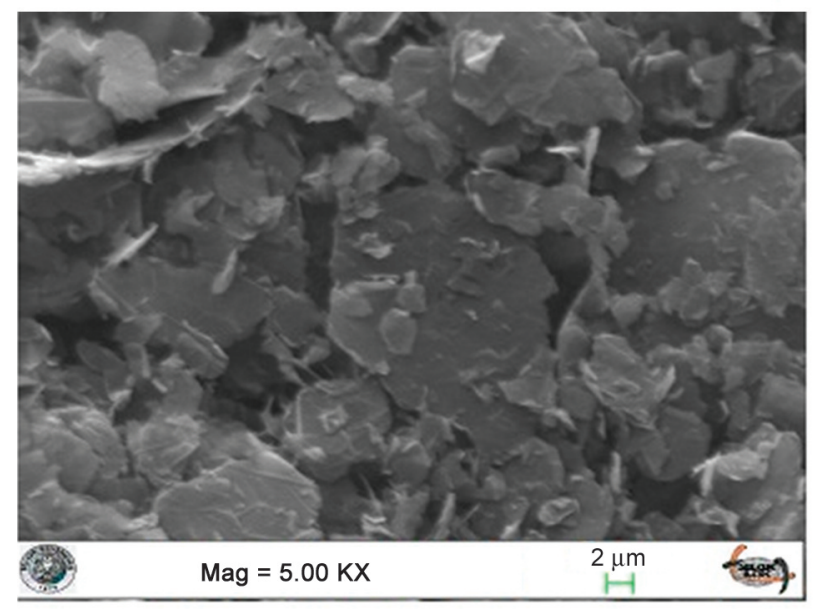

b)

Figure 3. SEM images of GNPs: a) u-GNP; b) PGMA-GNP.

[22]. The XRD patterns of the exfoliated GNPs (Figure 4a) show sharp and intense peaks that indicate a highly organized crystal structure. Two diffraction peaks were detected in both u-GNP and PGMA-GNP's XRD patterns at the same positions, suggesting that the GNP lattice was preserved after coating the GNPs with PGMA. The peak intensity of PGMA-GNP was lower than that of pristine GNP, proving that the GNP surface was coated with an amorphous polymer.

\subsubsection{TGA analysis}

Figure $4 \mathrm{~b}$ shows the TGA curves of the u-GNP and PGMA-GNP. TGA was conducted at $0-800^{\circ} \mathrm{C}$. The Tmain (main decomposition temperature), $T_{\max }$ (maximum weight loss temperature), char (residue at $800{ }^{\circ} \mathrm{C}$ ), and $T_{50}$ (temperature of $50 \%$ weight loss) of the GNPs are listed in Table 1 and were obtained from Figure $4 b$. Figure $4 b$ shows that the thermal degradation of u-GNP can be divided into two stages. GNP as a graphite intercalation product may consist of a small amount of oxygen groups on its surface
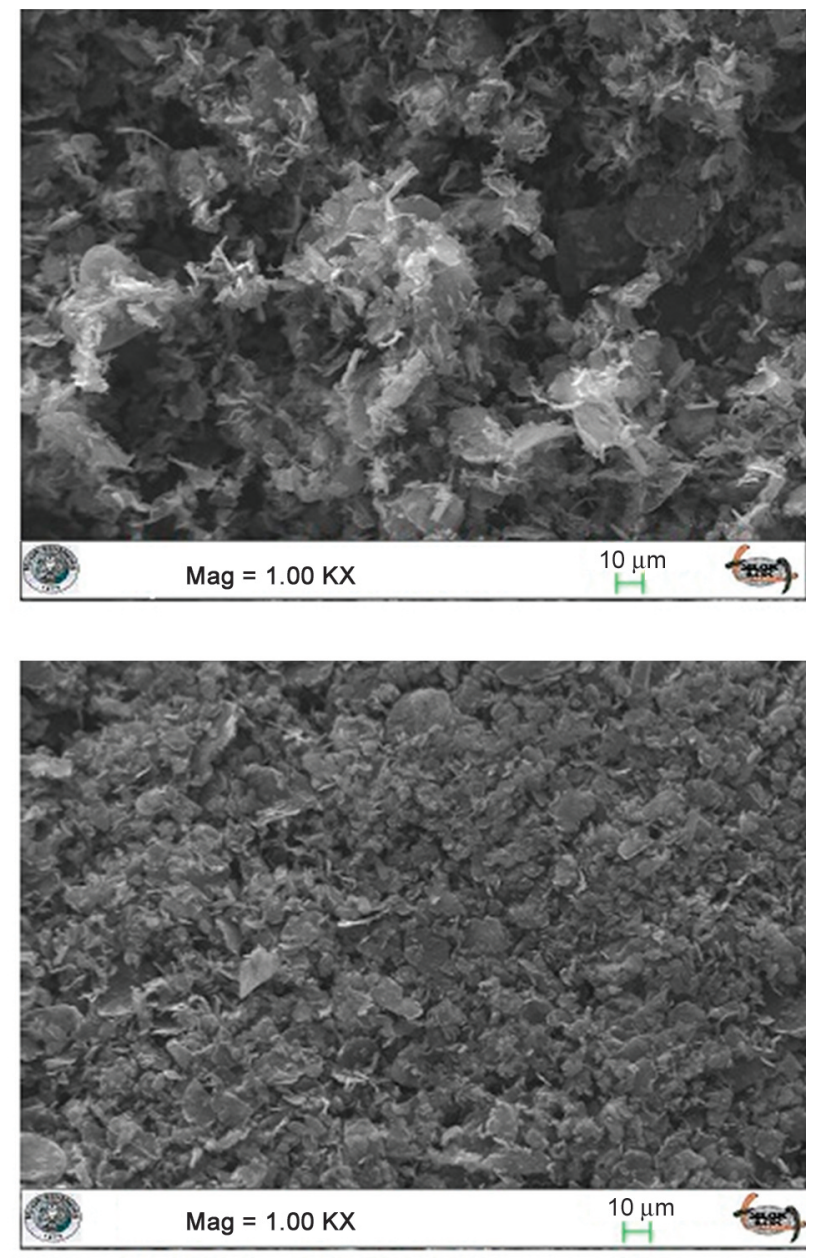

[26]. The first stage is defined as the thermal decomposition of oxygen-containing functional groups that occurs at $456-560^{\circ} \mathrm{C}$. As shown in Figure $4 \mathrm{~b}$, the thermal degradation of $\mathrm{u}-\mathrm{GNP}$ becomes unstable at $520^{\circ} \mathrm{C}$. The second stage begins at approximately $650^{\circ} \mathrm{C}$. At higher temperatures, carbon atoms may corrode or oxidize, resulting in the deformation of carbon bonds and the formation of void-like defects [35]. It is the opinion of the authors that because the unstable moieties are covered with the polymer, PGMA-GNP exhibits single-step degradation during heating. Both types of GNPs showed high thermal stability, but the $T_{5}$ (temperature of $5 \%$ weight loss; $485^{\circ} \mathrm{C}$ ) and $T_{10}$ (temperature of $10 \%$ weight loss; $537^{\circ} \mathrm{C}$ ) values of $\mathrm{u}-\mathrm{GNP}$ were higher than those of PGMA-GNP (378 and $399^{\circ} \mathrm{C}$, respectively) (see Figure 4b). From the literature, the thermal decomposition temperatures of various acrylate polymers are approximately $350-370^{\circ} \mathrm{C}$; moreover, most of these compounds degrade at approximately $420^{\circ} \mathrm{C}$ $[36,37]$. Accordingly, because of the PGMA polymer coating on the GNP surface, a decrease in the 

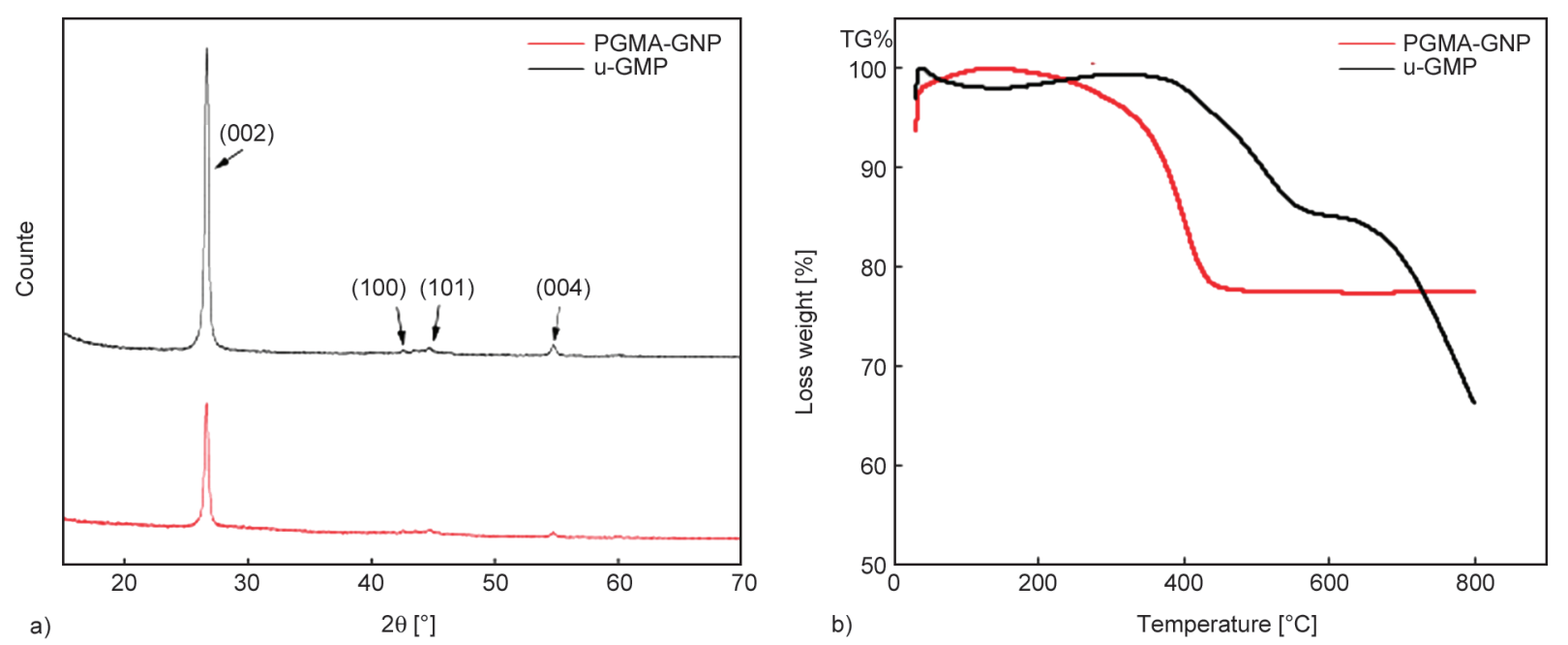

Figure 4. a) XRD patterns; b) TGA curves of u-GNP and PGMA-GNP.

thermal stability was observed at $400{ }^{\circ} \mathrm{C}$; however, above this temperature, the PGMA-coated GNPs were thermally more stable. This is because the GNP surface is covered with polymer residue during the PGMA decomposition, which makes the GNPs more resistant to subsequent decomposition. The residue weights at $800^{\circ} \mathrm{C}$ were 68.09 and $82.82 \%$ for u-GNP and PGMA-GNP, respectively, indicating the excellent thermal stability of these materials.

\subsection{Characterization of composites}

\subsubsection{SEM and TEM}

SEM analysis can provide insight into the adhesion and dispersion of nanoplatelets with a polymer matrix [38]. To understand the modification effect on dispersion, SEM micrographs were obtained from the PGMA-modified and u-GNP composites. Figure 5 shows SEM images of the neat ER, ER/uGNP, and ER/PGMA-GNP composites. A uniform epoxy breaking surface displays a smooth surface, which is a feature of a fragile structure [39]. Unlike the crack-prone surfaces of neat epoxy, the GNP composites exhibited a rough surface. Thermosetting resins are brittle and the addition of rough nanofillers prevents crack deviation.

GNPs may effectively inhibit crack propagation owing to their two-dimensional structure [40]. As seen from Figure 5b-5d, increasing the u-GNP content over $0.3 \mathrm{wt} \%$ led to agglomeration and more roughness in the microstructure, and the crack-like appearance slightly increased in size. The SEM image of the ER/1.5 wt $\%$ u-GNP showed that there were still some densely adhered agglomerates, which proves the difficulty of overcoming the high adhesion of
Van der Waals forces. Valley-like pores were also observed. SEM images of the composites revealed that the distribution of the PGMA-GNP nanofillers in the ER matrix was more homogenous than that of the ER/u-GNP composites (Figures $5 \mathrm{e}-5 \mathrm{~g}$ ). Coating the GNP surface with the polymer increased the filler matrix adhesion, which resulted in the significant reduction of pores and fissures. The PGMA-GNP particles with lower surface roughness, due to the PGMA coating only the outer surface of the GNPs, were saturated by ER, and there was no visible gap in the interface area, indicating that there may be good adhesion between the polymer and filler.

The number of large particles also decreased in the PGMA-GNP composites. Although PGMA-GNP composites have valley-like pores exceeding $0.3 \%$ by weight, very small crack-like appearances were detected. The SEM image of the composite with $0.5 \mathrm{wt} \%$ PGMA-GNP exhibited a better homogeneity and low surface roughness. Similarly, the best mechanical properties were achieved with the ER/0.3 wt $\%$ PGMA-GNP. The nanoplatelets added in small amounts are less likely to agglomerate in the resin, and the modification of fillers increases the compatibility between the filler and matrix, which may result in similar results. Additionally, small agglomerates contact each other to form a percolated network and may result in charge transfer or electrical conductivity between the graphene layers [22].

TEM analysis was performed to reveal the morphology of the GNPs. Because of the planar geometry of the GNPs, only the exposed edges of the GNPs were discernible in the SEM images. As depicted in Figure 6, the TEM images showed a typical GNP 


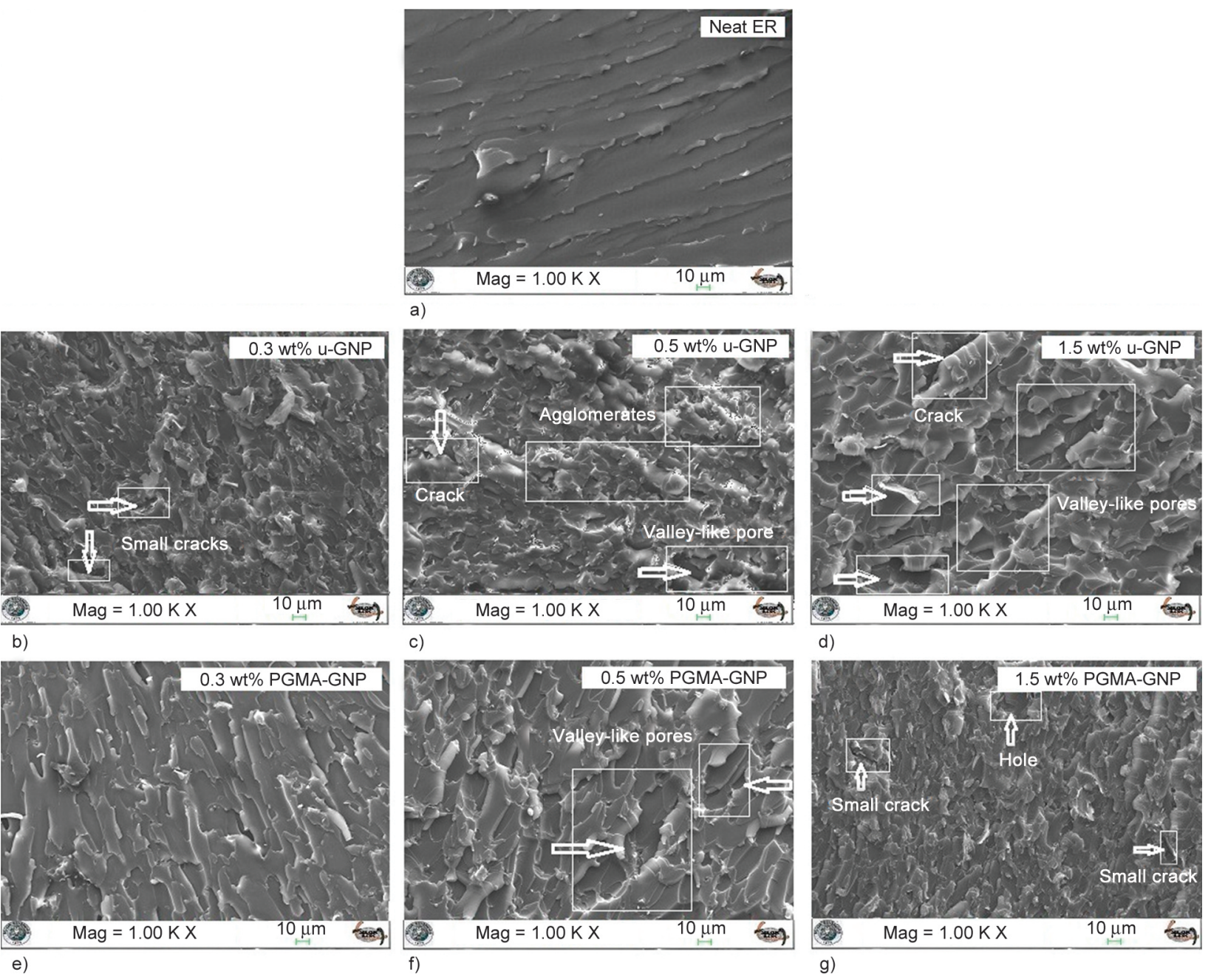

Figure 5. SEM images of neat ER (a), and composites with $0.3-0.5-1.5 \mathrm{wt} \%$ : u-GNP (b-d); PGMA-GNP (e-g).

structure that was wrinkled, similar to crumpled paper. This GNP structure is advantageous for promoting mechanical load transfer with the matrix [41]. In Figure 6, the most transparent regions are monolayer graphene, while the lighter areas show a thinner stack of GNP layers, and the dark areas show a thicker stack of GNPs [42]. The squares in Figure 6b

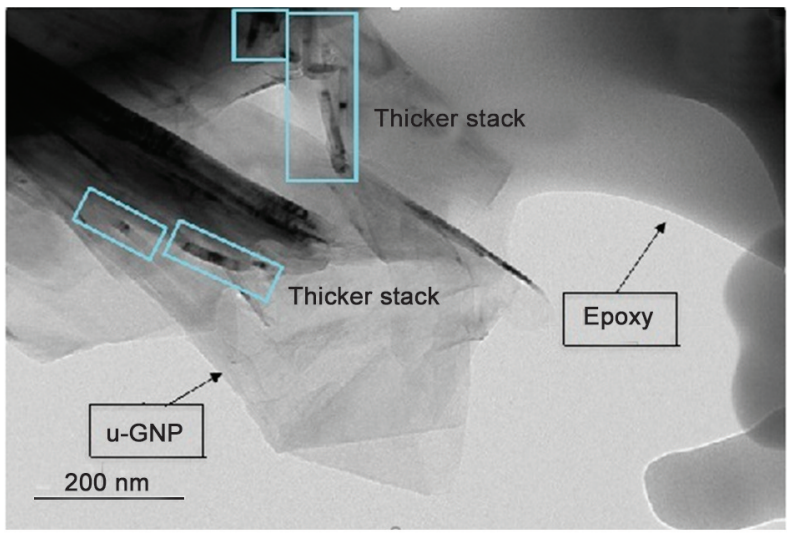

a) indicate the produced GNPs with a thickness exceeding $15 \mathrm{~nm}$ [43]. Agglomeration was clearly visible in the ER/2 wt\% u-GNP composite, while the ER/ $0.3 \mathrm{wt} \%$ PGMA-GNP composite showed a homogeneous dispersion, indicating that plasma polymerization increased the compatibility between the filler and matrix.

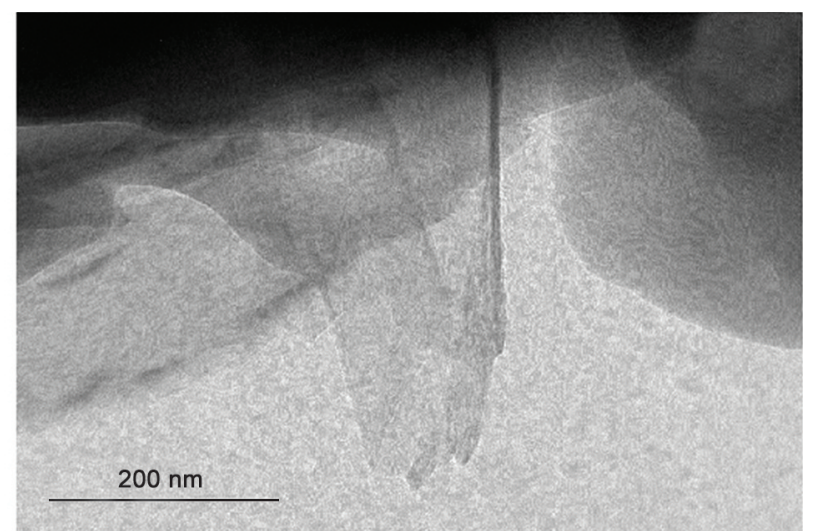

b)

Figure 6. TEM images of composites: a) ER/2 wt $\%$ u-GNP; b) ER/0.3 wt\% PGMA-GNP. 


\subsubsection{XRD}

The XRD diffraction pattern of the composites enables the quality of the filler dispersion to be compared. Figure 7 shows the XRD patterns of the neat epoxy, ER/u-GNP, and ER/PGMA-GNP composites. The characteristic $2 \theta$ degree of the neat epoxy was approximately $19^{\circ}$, and this wide peak corresponded to the amorphous polymer matrix, which was ER. The XRD patterns of the nanocomposites prepared with GNPs were very similar to those of the neat epoxy. As seen in the diffractograms in Figure 7, all nanocomposites were amorphous because they exhibited a large peak at $2 \theta=19^{\circ}$. Furthermore, the peak at $26.6^{\circ}$ was the characteristic $2 \theta$ of u-GNP, and the appearance of this peak indicated the agglomeration or a higher loading of nanofiller in the matrix [13]. A small peak at $26.6^{\circ}$ appeared in the ER/2.0 $\mathrm{wt} \% \mathrm{GNP}$ composite diffractogram, indicating the agglomeration of GNPs. A graphene peak was not observed for the ER/PGMA-GNP composites, suggesting that modifying the nanoplatelets by the PECVD method provided a more homogeneous dispersion.

\subsubsection{Mechanical properties}

GNPs improve the mechanical and electrical properties of polymer nanocomposites more than other carbon fillers or clay because of its larger surface area, increased contact area with the polymer matrix, and ability to maximize stress transfer from the polymer to the nanoplatelets [23, 24]. Figure 8 illustrates the variation in tensile strength, elongation at break, Young's modulus, and hardness of the epoxy composites with different GNP loadings.

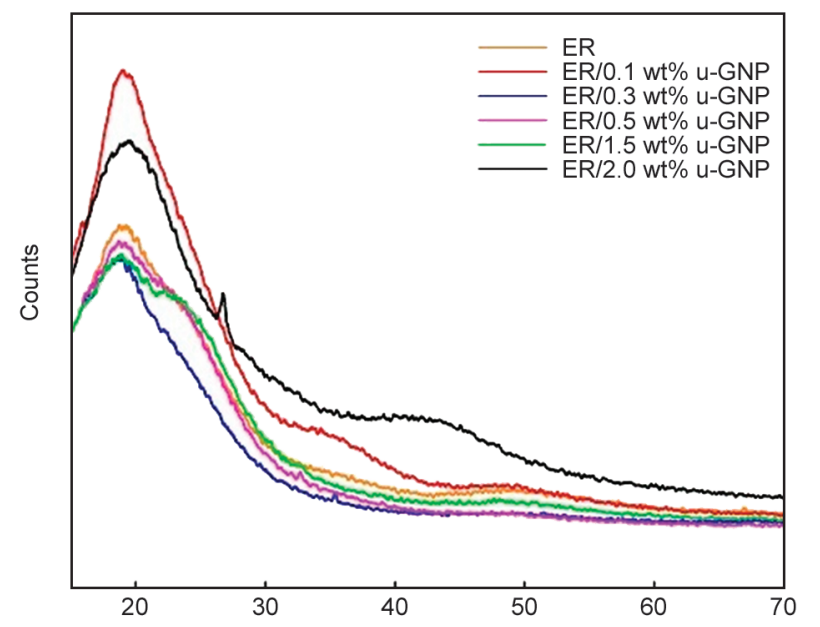

a) $2 \theta\left[{ }^{\circ}\right]$
The mechanical test data determined for ER were: tensile strength $=95 \mathrm{MPa}$; e-modulus $=4.6 \mathrm{GPa}$; elongation $=1.39 \%$; and hardness $=70$ Shore D. The tensile strengths of all the u-GNP and PGMA-GNP composites were higher than those of neat epoxy. The highest tensile strength in the ER/u-GNP composites was achieved with the addition of $0.1 \mathrm{wt} \%$ u-GNPs, while the lowest tensile strength value was obtained with the addition of $2.0 \mathrm{wt} \% \mathrm{u}$-GNPs, achieving values of 150 and $98 \mathrm{MPa}$, respectively. The highest tensile strength in the ER/PGMA-GNP composites was obtained with the addition of $0.3 \mathrm{wt} \%$ PGMA-GNP, while the lowest tensile strength value was obtained with the addition of $2.0 \mathrm{wt} \%$ PGMAGNP, achieving 180 and $108 \mathrm{MPa}$, respectively. The tensile strength of the ER/PGMA-GNP composites decreased after $0.3 \mathrm{wt} \%$. Additionally, the tensile strength values of the ER/PGMA-GNP composites were found to be generally higher than that of the ER/u-GNP composites (Figure 8a). The reason for the higher tensile strength of the ER/PGMA-GNP composites may be that the epoxy groups in the PGMA structure create a good interface interaction with the ER. Thus, the filler may exhibit better dispersion in the ER, resulting in a higher tensile strength of the composite material. Lan et al. [44] reported that by grafting PGMA chains onto the carbon fiber (CF) surface, the roughness and number of active $\mathrm{CF}$ groups that enhance the interface and mechanical properties of the composites could be significantly increased. In another study investigating the effect of PGMA, it was stated that the coating of aramid fibers with PGMA not only increased the polar group

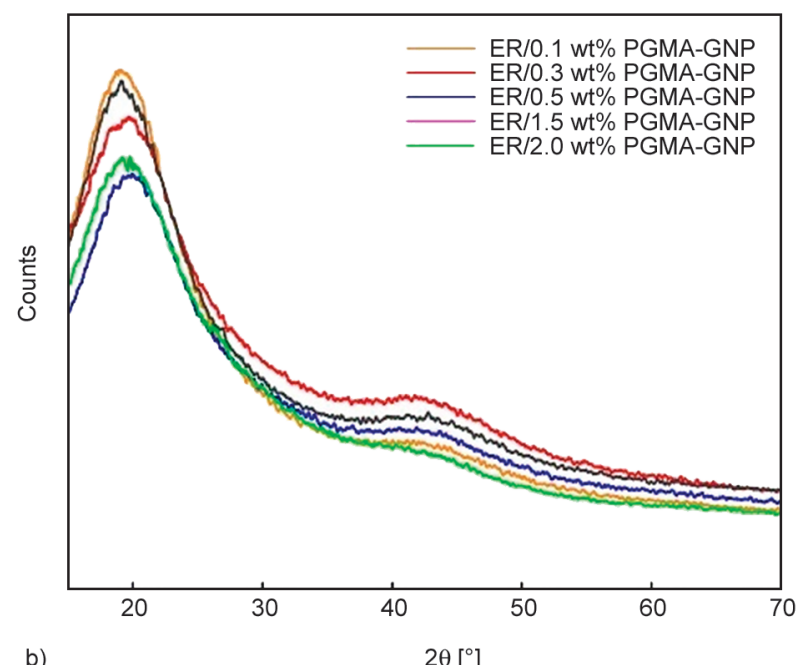

b)

$2 \theta\left[^{\circ}\right]$

Figure 7. XRD patterns of neat ER and composites with $0.1-0.3-0.5-1.5-2.0 \mathrm{wt} \%$ : a) u-GNP; b) PGMA-GNP. 
content and surface free energy and roughened the surface, but also increased the mechanical properties while maintaining excellent thermal resistance [45]. The Young's modulus values of both types of GNP composites were also higher than that of neat epoxy (Figure $8 b$ ). The reason for this may be that GNP has a very high Young's modulus, even though it is used in very low amounts. In terms of tensile strength, at the most appropriate additions of $0.1 \mathrm{wt} \% \mathrm{u}-\mathrm{GNP}$ and $0.3 \mathrm{wt} \%$ PGMA-GNP, Young's modulus values of the nanocomposites were 4.9 and $6.1 \mathrm{GPa}$, respectively. The increases in Young's modulus and tensile strength for the ER/u-GNP composites were determined to be $6.52-30.43$ and $3.16-57.89 \%$, respectively, and those for the ER/PGMA-GNP composites were determined to be 26.09-34.78 and 13.68$89.47 \%$, respectively, as compared to neat ER. Additionally, polymer coating enhanced the tensile strength and Young's modulus of the PGMA-coated GNP composites by $10.2-20$ and $3.3-18.4 \%$, respectively, as compared to the ER/u-GNP composites. Figure 8 shows a difference in Young's modulus between the treated and untreated GNPs with an increasing GNP content. A significant increase of up to $0.3 \%$ by weight was observed in Young's modulus values of the u-GNP composites, and these values

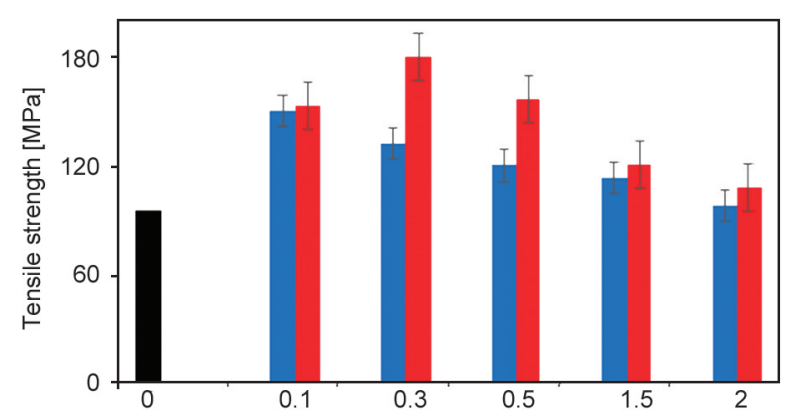

a)

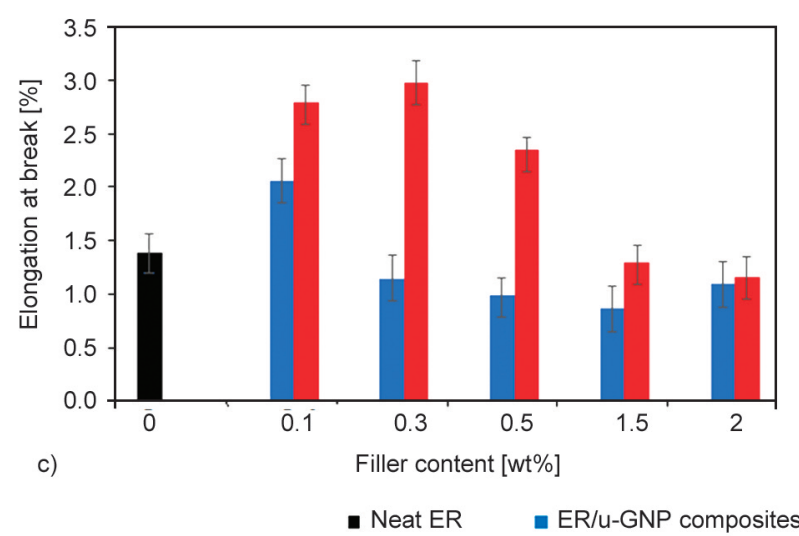

were similar to each other with a slight decrease in the mass ratio of fillers. In contrast, Young's modulus values of the PGMA-GNP composites were high and showed a slight increase at a $0.5 \%$ mass ratio of fillers, while a slight decrease was detected above $0.5 \mathrm{wt} \%$. These results revealed that coating GNPs with PGMA was more effective for Young's modulus, even at $0.1 \mathrm{wt} \%$.

The elongation at break of the composites was similar to that of the tensile strength [46].

At a $0.1 \mathrm{wt} \%$ filler content, the elongation at break of the u-GNP decreased depending on the filler rate, and it exhibited lower values than pure epoxy (Figure 8c). This can be explained by the tendency for graphene agglomeration. The literature shows that graphene tends to agglomerate in the matrix owing to its large surface area and strong Van der Waals forces; thus, agglomeration of filler particles in the epoxy adversely affects the end-product properties. Powdery fillers generally reduce the elongation of the matrix, but it has been reported that elongation may increase if the filler is nano-sized [47, 48]. Moreover, our previous studies showed that modification of various filler surfaces with poly(hexafluorobutyl acrylate) by the PECVD method increased their compatibility with the epoxy matrix. Consequently, the
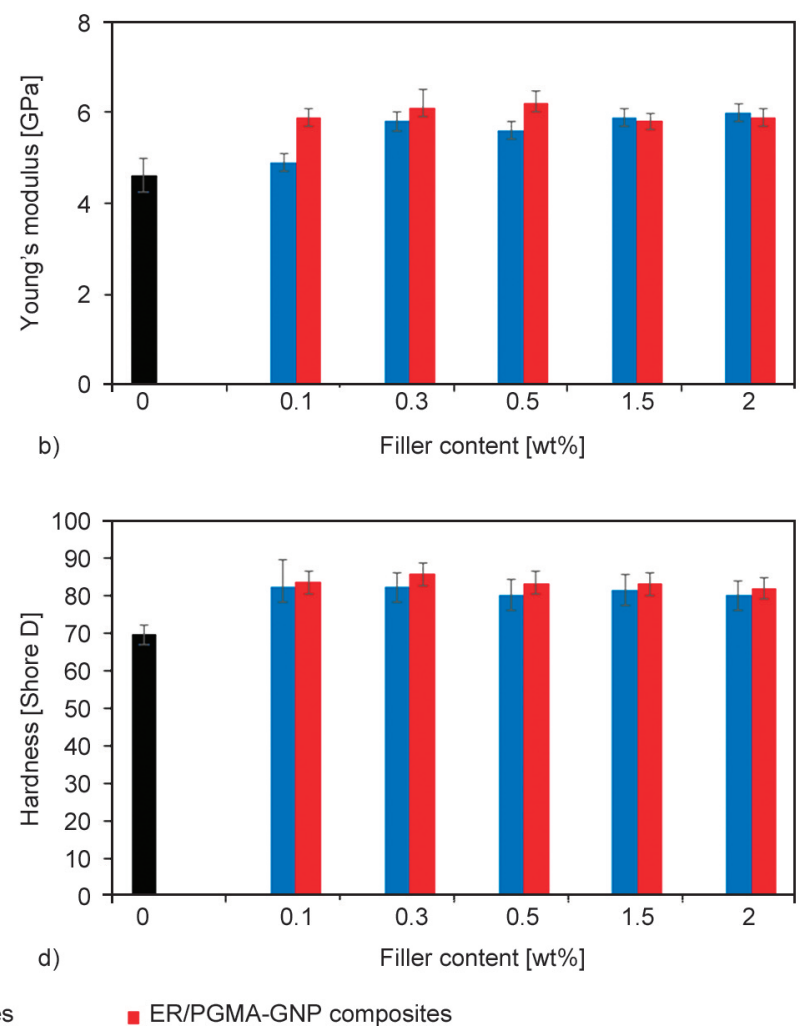

Figure 8. Mechanical behavior of neat ER and composites: a) tensile strenght; b) Young's modulus; c) elongation at break; d) hardness. 
micro-voids and holes in the composite structure were decreased owing to the developed filler-matrix interaction, which resulted in enhanced properties [3]. Naeem et al. [24] also attributed the development of mechanical properties of composites to strong molecular interactions between graphene and epoxy because of the rich oxygen functional groups on the graphene surface.

Figure $8 \mathrm{~d}$ presents the hardness values of the GNP composites. The hardness of all the composites was higher than that of pure epoxy. The highest hardness value in the ER/u-GNP composites was obtained at $0.1 \mathrm{wt} \%$, while the maximum hardness value in the ER/PGMA-GNP composite was achieved at $0.3 \mathrm{wt} \%$. The modified GNPs appeared to have little effect on the hardness of the material. Although all the hardness values were higher than those of pure epoxy, there was no continuous increase in the hardness values of the composites with the addition of fillers, and the values were found to be similar to each other, probably due to the low amounts of GNPs.

\subsubsection{Thermal properties}

Thermal properties and thermal stability are important factors in determining the performance of polymeric materials. Generally, GNPs remove free radicals that initiate the decomposition of polymers and have a barrier effect, so they are known to improve thermal stability [48]. The literature confirmed that filling the polymer with GNPs enhances the thermal and mechanical properties. Additionally, the filler content and its distribution in the resin matrix greatly affect the thermal stability and thermal properties of the material $[11,26]$. The thermal stability and thermal
Table 1. Thermal data of the GNPs and composites obtained from the TGA thermograms.

\begin{tabular}{|c|c|c|c|c|}
\hline $\begin{array}{c}\text { Filler } \\
\text { [wt\%] }\end{array}$ & $\begin{array}{l}T_{\text {main }} \\
{\left[{ }^{\circ} \mathbf{C}\right]}\end{array}$ & $\begin{array}{l}\boldsymbol{T}_{\max } \\
{\left[{ }^{\circ} \mathbf{C}\right]}\end{array}$ & $\begin{array}{c}T_{50} \\
{\left[{ }^{\circ} \mathbf{C}\right]}\end{array}$ & $\begin{array}{c}\text { Char } \\
{[\%]}\end{array}$ \\
\hline \multicolumn{5}{|c|}{ u-GNP } \\
\hline 100 & 456 & 839 & - & 68.09 \\
\hline \multicolumn{5}{|c|}{ PGMA-GNP } \\
\hline 100 & 470 & 471 & - & 82.82 \\
\hline \multicolumn{5}{|c|}{ Neat ER } \\
\hline- & 386 & 753 & 392 & 2.58 \\
\hline \multicolumn{5}{|c|}{ ER/u-GNP composites } \\
\hline 0.1 & 391 & 515 & 392 & 7.61 \\
\hline 0.3 & 395 & 514 & 394 & 8.14 \\
\hline 0.5 & 385 & 504 & 395 & 8.27 \\
\hline 1.5 & 384 & 494 & 393 & 8.30 \\
\hline 0.2 & 383 & 491 & 390 & 8.43 \\
\hline \multicolumn{5}{|c|}{ ER/PGMA-GNP composites } \\
\hline 0.1 & 393 & 517 & 392 & 8.30 \\
\hline 0.3 & 394 & 507 & 391 & 8.56 \\
\hline 0.5 & 387 & 506 & 393 & 8.59 \\
\hline 1.5 & 383 & 504 & 390 & 8.35 \\
\hline 0.2 & 382 & 500 & 391 & 8.54 \\
\hline
\end{tabular}

properties of epoxy composites filled with GNPs with two different structures (u-GNP and PGMAGNP) were measured using thermogravimetric analysis. The TGA curves of both ER/GNP composite systems are presented in Figure 9, including the ER/ u-GNP composites in Figure 9a and the ER/PGMAGNP composites in Figure 9b. Table 1 lists the thermal stability parameters predicted from the TGA thermograms.

Table 1 shows that the thermal degradation process of both composite systems in the nitrogen atmosphere is similar to that of the pure ER, which may

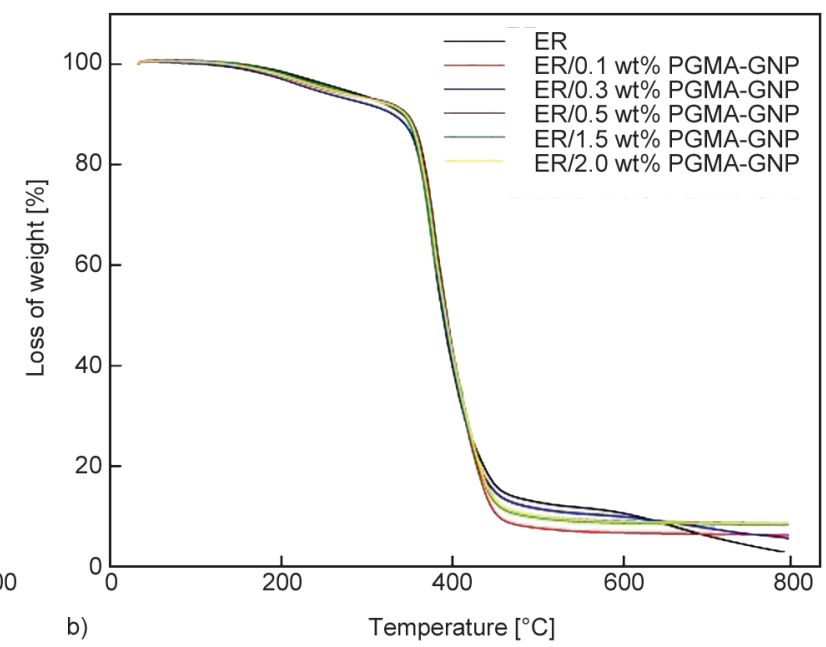

Figure 9. TGA curves of neat ER and composites with: a) u-GNP; b) PGMA-GNP. 
arise from the low filler loading. The $T_{\text {main }}$ of the composites was higher than that of the ER up to $0.3 \mathrm{wt} \%$. Agglomeration above $0.5 \mathrm{wt} \%$ of filler loading resulted in a small reduction in the $T_{\text {main }}$ of the composites, while a very small decrease in the $T_{\max }$ values may be associated with an increase in the amount of GNPs [48]. Moreover, the results showed that the effect of GNP modification on thermal stability was insignificant, probably because the polymer coating was nanometer-thick. The $T_{\max }$ values of all the composites were lower than those of neat ER, and the maximum weight loss was fixed at approximately $500^{\circ} \mathrm{C}$, which indicated that the composites were thermally more stable at temperatures exceeding $500^{\circ} \mathrm{C}$. The residual amount of nanocomposites increased with an increasing GNP content, resulting in a delay in the thermal decomposition of the ER in the nanocomposite, which was due to the GNP having a maximum decomposition temperature of approximately $500^{\circ} \mathrm{C}$.

\subsubsection{Electrical conductivity}

Graphene has a very high electrical conductivity [49]. The electronic properties of graphene depend on its fully symmetrical and two-dimensional structure. Neat epoxy without conductive additives is an insulating material. Figure 10 shows the electrical conductivity values of the composites. The electrical conductivity of neat ER, as measured using a four-probe method, was approximately $10^{-14} \mathrm{~S} / \mathrm{cm}$. Figure 10 shows that the GNPs increased the electrical conductivity of the ER, regardless of modification. A significant increase in electrical conductivity from $10^{-14}$ to $10^{-7} \mathrm{~S} / \mathrm{cm}$ was observed for a $0.1 \mathrm{wt} \%$ content of both types of GNP.

Moreover, for both types of GNP fillers, the electrical conductivity of the epoxy composites steadily increased in the range of $0.1-0.5 \mathrm{wt} \%$, while contents above this loading did not yield further significant

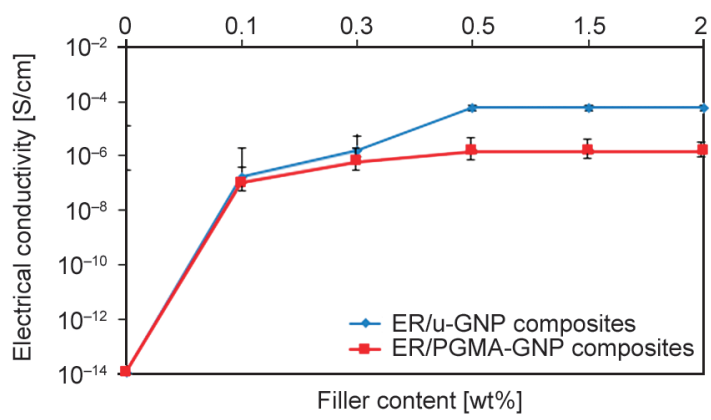

Figure 10. Electrical conductivity of the composites as a function of the filler weight fraction. increases. The electrical conductivity values of $0.5 \mathrm{wt} \% \mathrm{u}-\mathrm{GNP}$ and PGMA-GNP composites were measured as $5.86 \cdot 10^{-5}$ and $1.48 \cdot 10^{-6} \mathrm{~S} / \mathrm{cm}$, respectively. These results showed that GNPs effectively improved the electrical conductivity of the epoxy. The increase in conductivity due to the addition of GNPs into the epoxy is due to the formation of an interconnected graphene network which facilitates the transport of electrons along the polymeric matrix. Because the electrical conductivity increased by approximately six orders of magnitude up to $0.1 \%$ by weight, the electrical percolation thresholds of both types of nanocomposites were approximately $0.1 \mathrm{wt} \%$; that is, the nanocomposites showed a rapid transition to an electrical semiconductor state [22]. The electrical conductivity of the composites with PGMAGNP was relatively lower than those with u-GNP, possibly because of the non-conductive PGMA.

\subsubsection{Wettability, water sorption, and anticorrosion properties}

The CA of hydrophobic surfaces is higher than $90^{\circ}$ [50]. A previous study reported that a higher CA is a sign of lower water absorption [51]. Consequently, for wetted, non-wetted, and intermediate wetted surfaces, the CAs were approximately $60-75,105-120$, and $75-105^{\circ}$, respectively. GNPs are hydrophobic materials, but their hydrophobicity largely depends on thickness; that is, thinner layers are more hydrophilic, which increases the fluid bridging forces between the graphene layers [52, 53]. Figure 11 shows the CA measurement results for the GNP composites. The CA of neat ER was $82.7^{\circ}$, while that of the composites changed in the range of 93-102.7 and 96.3$103.4^{\circ}$ for the u-GNP and PGMA-GNP composites, respectively. This data shows that the reinforcement of ER with GNPs increased the CA of the neat resin. It is the opinion of the authors that the GNPs became more hydrophobic after chemical modification with PGMA, which is a hydrophobic polymer [54]. As reported by Pinto et al. [55], the equilibrium CA for water in dry PVAc films increased by $13^{\circ}$ upon the addition of $0.1 \%$ GNPs by weight due to the hydrophobicity of the GNPs. The same result was achieved in our previous study in which a hydrophobic poly(hexafluorobutyl acrylate) (PHFBA) polymer coating on the surface of the fillers increased the CA value of the composites [3].

The water sorption tests of the composites were conducted for a period of $25 \mathrm{~d}$. Figure 11a shows the 


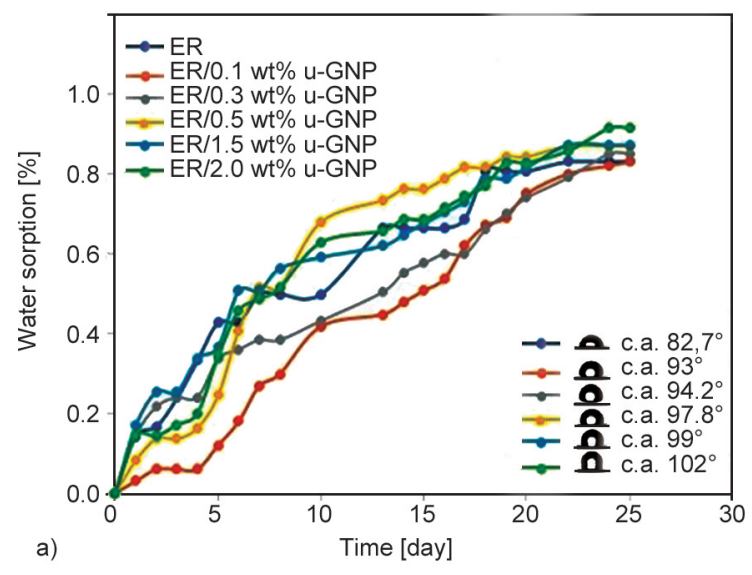

ER/u-GNP composites structures

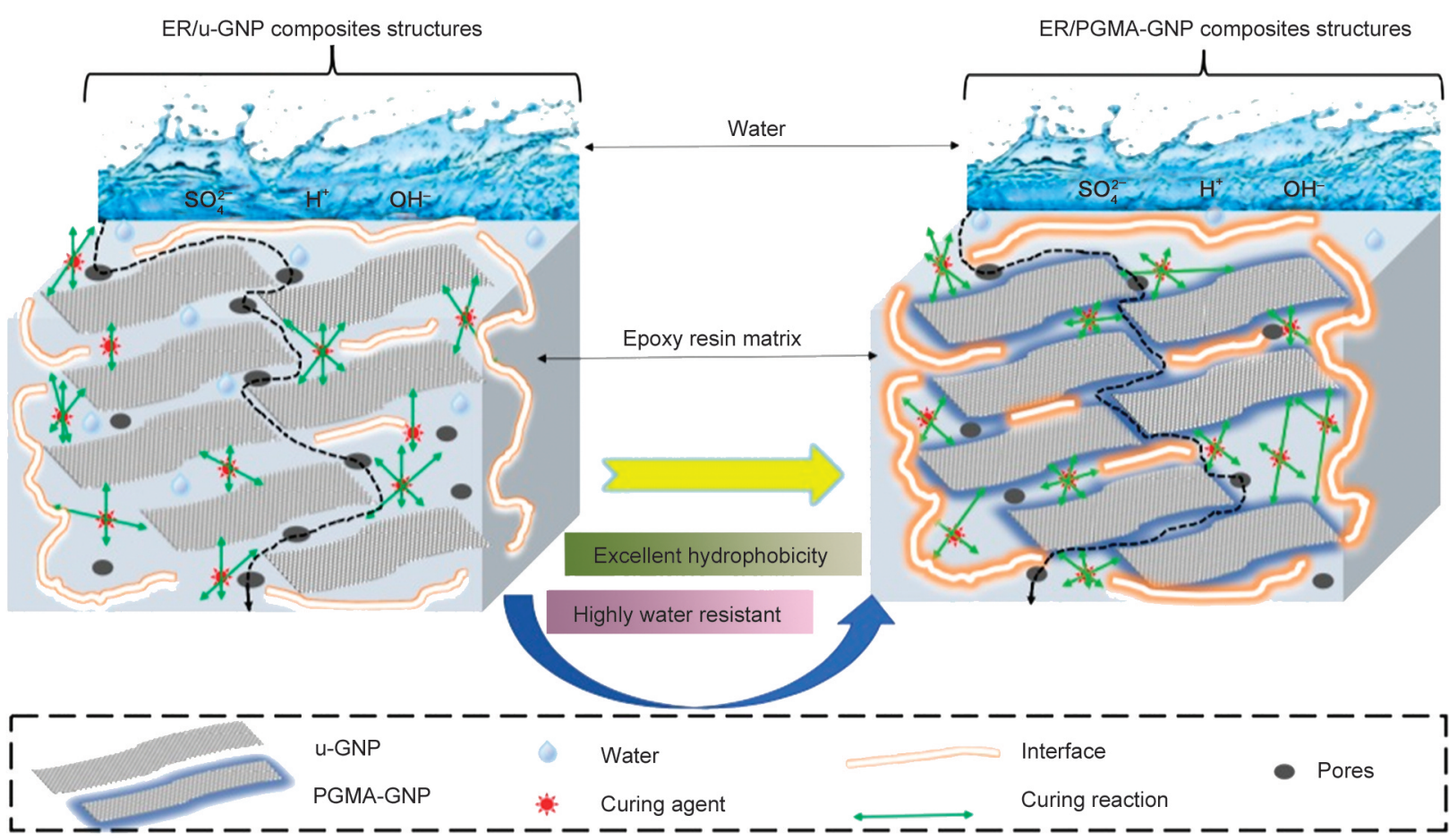

b)

Figure 11. a) Water sorption curves and CA values of neat ER, ER/u-GNP and ER/PGMA-GNP composites; b) water sorption and corrosion protection mechanism of composites.

water sorption test results of the ER/u-GNP and ER/PGMA-GNP composites.

As seen in Figure 11a, the water sorption percentage of the neat ER after $25 \mathrm{~d}$. was $0.83 \%$. The water sorption of the composites occurred faster in the first 7$10 \mathrm{~d}$ and generally reached a balance after $20 \mathrm{~d}$. The water sorption ranged from 0.83 to 0.91 and 0.59 to $0.81 \%$ for the ER/u-GNP and ER/PGMA-GNP composites, respectively. Depending on the ratio of filler, the water sorption of the ER/u-GNP composites was found to be close to or slightly higher than that of neat epoxy, while the water sorption of the ER/ PGMA-GNP composites was found to be less than that of neat epoxy. Although a negligible increase in

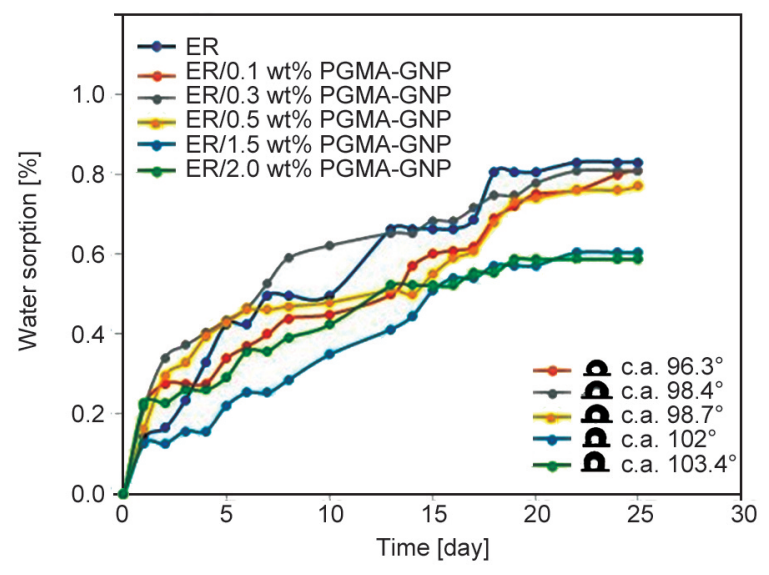

ER/PGMA-GNP composites structures

\section{(n)}

\section{(n)}


decreased as a result of modifying GNP with PGMA (Figures 5e-5g), which caused a decrease in water sorption. Furthermore, PGMA increased the hydrophobicity of the composites, causing a decrease in water sorption (Figure 11b). Hydrophobicity is one of the properties of coatings. Higher hydrophobicity prevents water from reaching the lower layer and protects the coating from segregation [1]. In addition to the properties observed in our work, graphene offers other desirable properties, such as a high strength/ weight ratio, impermeability, and chemical inertness. These features enable more environmentally friendly composites to be obtained when graphene is used as an additive in the polymer matrix to prevent corrosion. In particular, the cathodic protection technique is used to control the corrosion of a metal surface by making the material to be protected by the cathode of an electrochemical cell. This simple protection technique connects the metal to be protected to a more easily corroded 'sacrificial metal', which acts as the anode. In recent years, the role of graphene in increasing the corrosion resistance of zinc-rich coatings has been investigated, resulting in the development of coatings with reduced zinc content and increased cathodic protection [1, 57]. Zhang et al. [58]

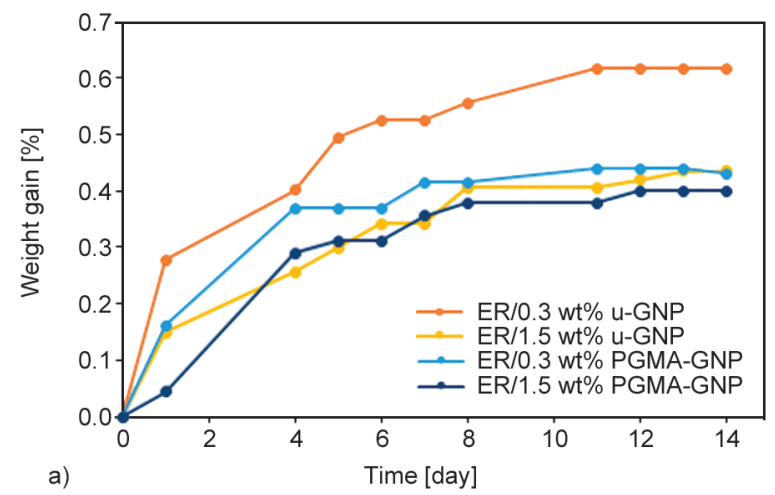

reported that the GNP-based epoxy resin coating with good mechanical properties presented better corrosion resistance.

Most studies have investigated the corrosion resistance of graphene composite coatings in low salinity or acid solutions, while there are very few studies on their resistance in environments containing high concentrations of salt, bases, or acids [59]. To determine the corrosion properties of the ER/u-GNP and ER/PGMA-GNP composites, samples with 0.3 and $1.5 \mathrm{wt} \%$ GNPs were maintained in highly corrosive environments, that is, $10 \% \mathrm{NaCl}, \mathrm{NaOH}$, or $\mathrm{H}_{2} \mathrm{SO}_{4}$ solutions for $14 \mathrm{~d}$. Figure 12 shows the corrosion test results, and Figures 13 and 14 show the SEM and microscope images of the PGMA-GNP composites, respectively.

Xu et al. [2] reported that an epoxy coating modified with hydrophobic nano-silica exhibited better corrosion resistance than an epoxy coating modified by hydrophilic nano-silica. This may be because hydrophobicity can repel water and corrosive ions from the coating surface and delay their transport in the coating. In our study, the hydrophobicity of the ER/u-GNP and ER/PGMA-GNP composites was already high, and coating the GNPs with PGMA

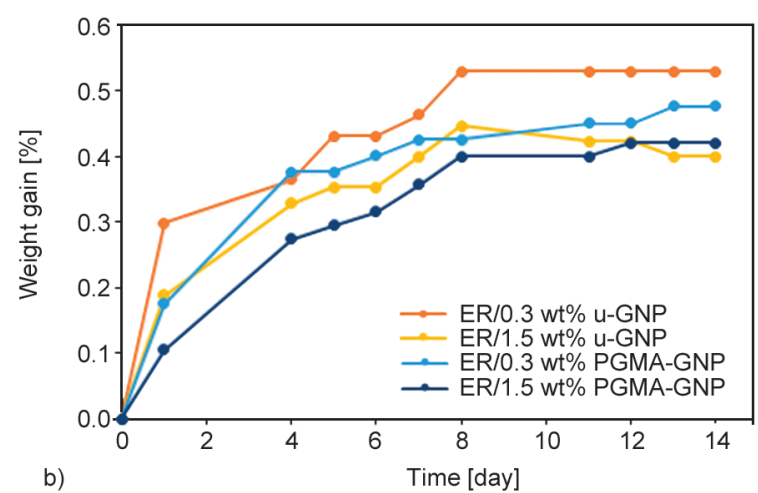

b)

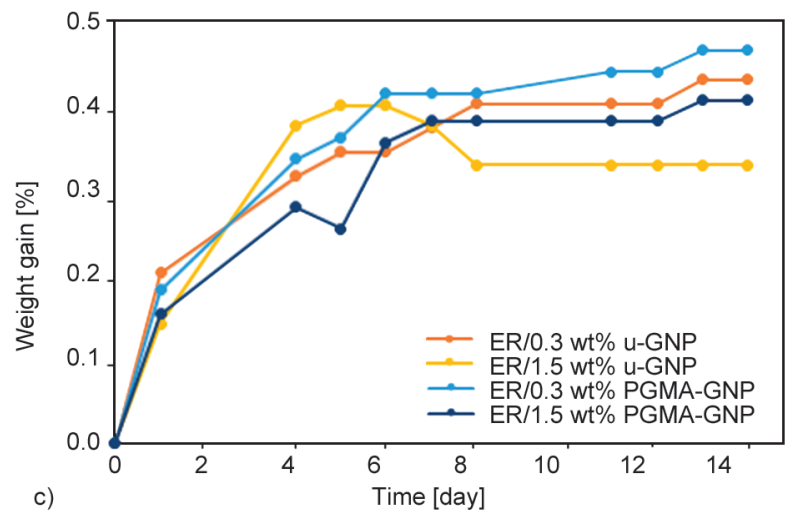

Figure 12. Weight change curves of composites with 0.3 and $1.5 \mathrm{wt} \%$ GNPs in high corrosive environment: a) $10 \% \mathrm{NaCl}$; b) $10 \% \mathrm{NaOH}$; c) $10 \% \mathrm{H}_{2} \mathrm{SO}_{4}$. 
increased the hydrophobicity. As can be seen from Figure 12, the nanocomposites showed high resistance to highly corrosive environments and a low mass increase. This may be because composites can absorb various ions in solutions, apart from water molecules. The composites with $1.5 \% \mathrm{u}$-GNP by weight exhibited a slightly different behavior from those of the other composites. The maximum weight gains of the $1.5 \mathrm{wt} \% \mathrm{u}-\mathrm{GNP}$ composites in basic and acidic environments were 0.4461 and $0.3973 \%$, respectively, and decreased to 0.3992 and $0.3272 \%$ after approximately one week. The mass losses of the $1.5 \mathrm{wt} \% \mathrm{u}$-GNP composites because of weak corrosion were approximately 0.046 and $0.07 \%$, respectively. These mass losses may not be considered significant, as the mass change remained constant thereafter. The tortuous passage of corrosive ions through epoxy composites may explain why the addition of exfoliated GNPs to epoxy effectively improves the corrosion resistance of epoxy composites in high salt, basic, and acidic environments [60], hindering their ability to reach the metal (Figure 11b). It has also been stated in the literature that three factors are important in the corrosion resistance of the nanocomposite coating, namely, 1) creating a zigzag diffusion path for corrosive ions owing to the high surface area of graphene, 2) ensuring good adhesion of the cured epoxy, and 3) preventing electrons from forming the cathodic region by providing an alternative pathway with functionalized graphene and excellent electrical conductivity [1]. Moreover, PGMA-GNP composites generally have less mass increase than u-GNP composites and are considered to be more resistant to corrosion. For all three corrosive environments, the mass increase was higher in both types of $0.3 \mathrm{wt} \%$ composites. To achieve sufficient corrosion efficiency for the epoxy coating, the ratio of graphene is generally greater than $0.5 \%[57$, $58,61,62]$. Therefore, the graphene ratio may not be sufficient in the $0.3 \mathrm{wt} \%$ composites. Because better results were obtained with the PGMA-GNP composites, these composites were chosen for SEM and microscopy images. The SEM image of the $0.3 \%$ composite in a saline environment clearly shows that rectangular- and square-shaped $\mathrm{NaCl}$ crystals diffused into the composite (Figure 13a), while this was not detected in the $1.5 \mathrm{wt} \%$ composite (Figure 13d). The SEM images of this composite before (Figure 5e) and after being maintained in a basic and acidic environment were compared. It was clear that there was no abrasion in the $\mathrm{NaOH}$ environment (Figure 13b), but deep cracks were visible, and in the acidic environment, the surface became significantly rougher and voids were formed (Figure 13c). In contrast, the $1.5 \mathrm{wt} \%$ PGMA-GNP composite exhibited no cracks or large voids in the basic and acidic environments (Figure 13e and 13f). This was confirmed by microscopy images taken from sections of the composites.

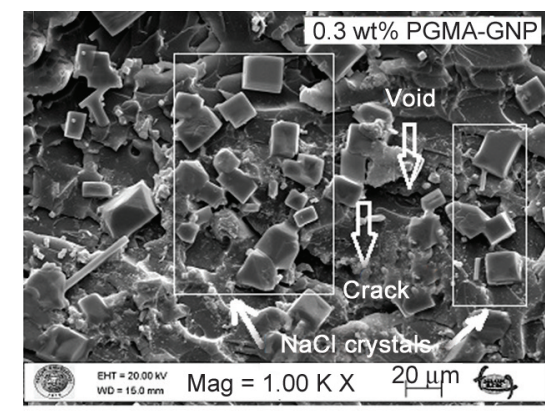

a)

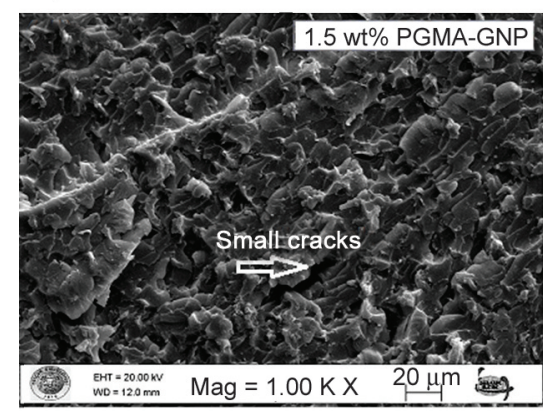

d)

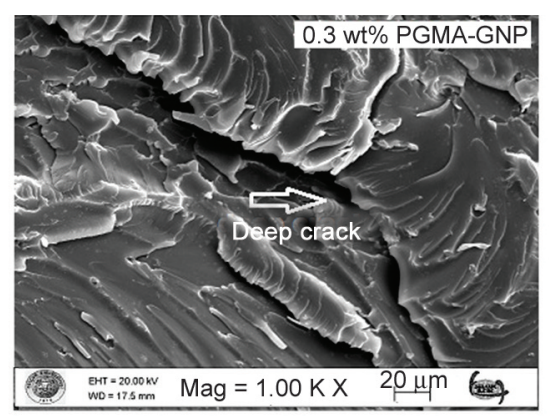

b)

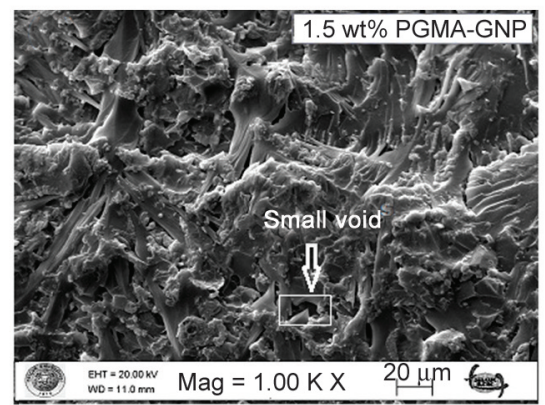

e)

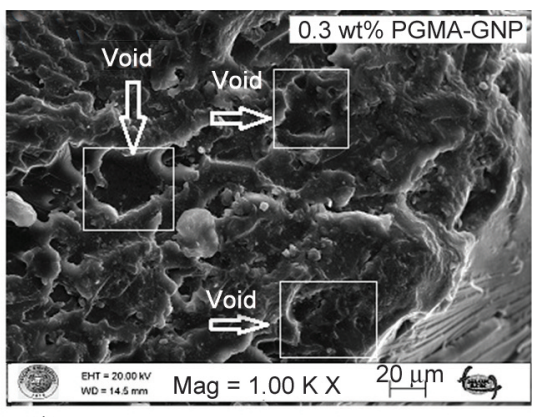

c)

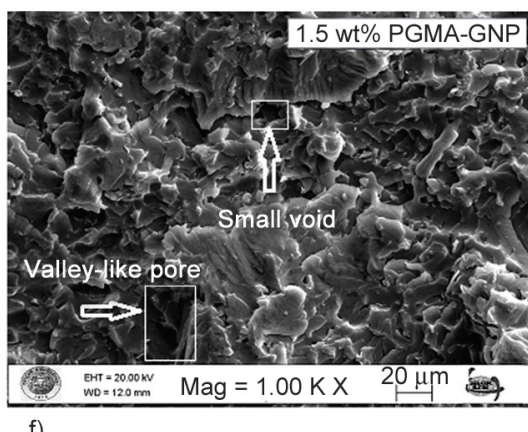

Figure 13. SEM images of composites with: (a-c) 0.3 wt $\%$ PGMA-GNP; (d-f) 1.5 wt $\%$ PGMA-GNP in $10 \% \mathrm{NaCl}, 10 \%$ $\mathrm{NaOH}$ and $10 \% \mathrm{H}_{2} \mathrm{SO}_{4}$, respectively. 


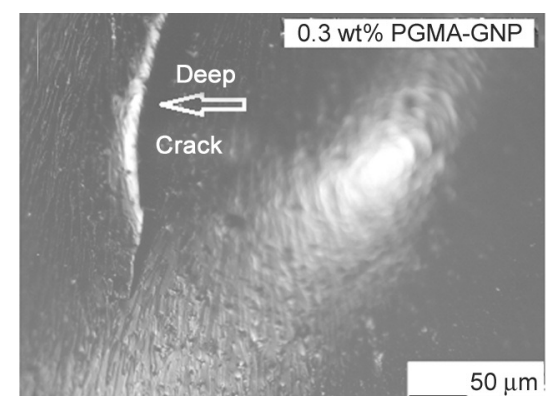

a)

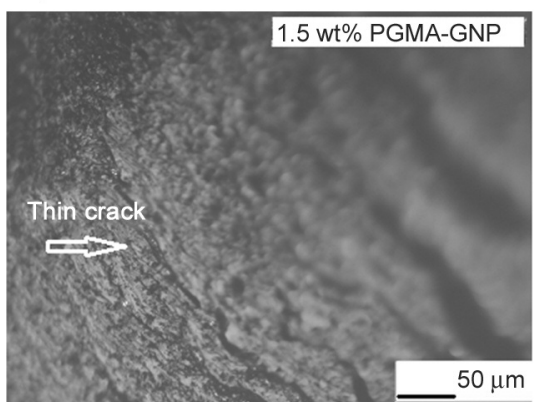

d)

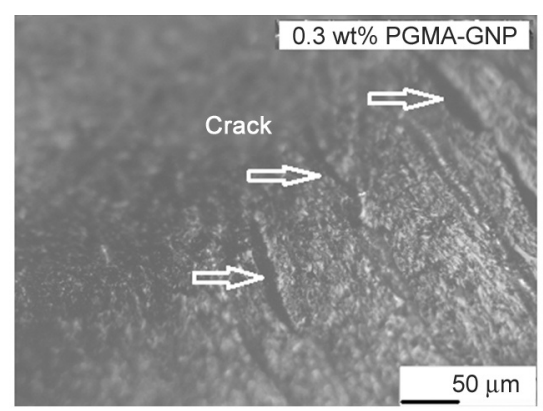

b)

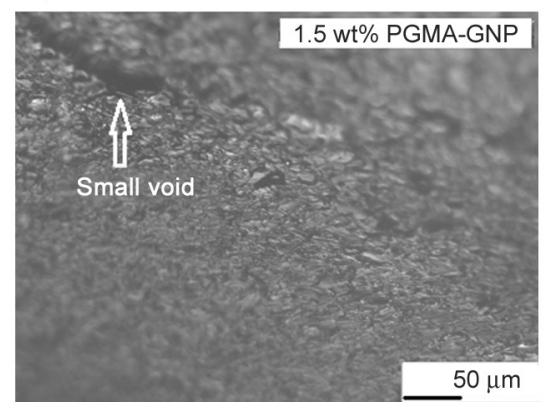

e)

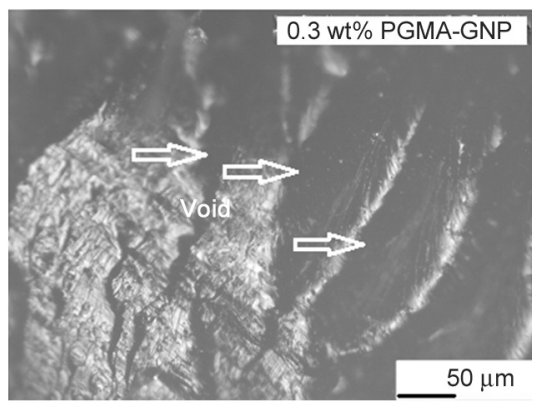

c)

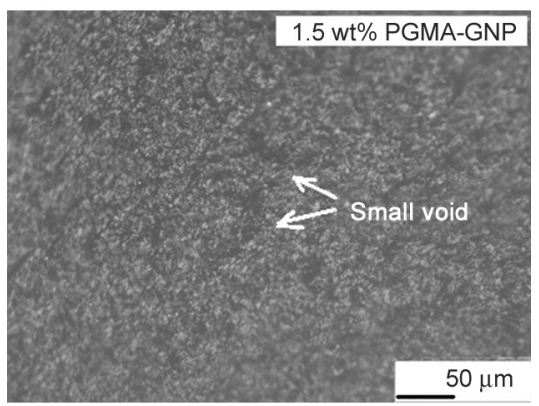

f)

Figure 14. Microscope images of composites with: (a-c) 0.3 wt $\%$ PGMA-GNP; (d-f) 1.5 wt $\%$ PGMA-GNP in $10 \%$ NaCl, $10 \% \mathrm{NaOH}$ and $10 \% \mathrm{H}_{2} \mathrm{SO}_{4}$, respectively.

The number of cracks observed in the $0.3 \mathrm{wt} \%$ composite increased in the salt-base-acid direction (Figure 14a-14c). In contrast, the $1.5 \mathrm{wt} \%$ composite was not, or only slightly, affected by the corrosive environments (Figure 14d-14f). Consequently, the immersion test in various aggressive environments showed that the composite containing 1.5\% PGMAGNP by weight and the barrier effect of the epoxy graphene nano sheets greatly improved the corrosion resistance.

\section{Conclusions}

This study presents the novel demonstration of the properties of epoxy nanocomposites filled with synthesized $\mathrm{u}$ - and PGMA-coated GNPs. The surfaces of the GNPs were chemically modified by the PECVD method, and the surface coating was confirmed by FT-IR and SEM. The structural properties of the GNPs were characterized by XRD analysis. Although the thermal resistance of PGMA-GNP decreased below $400^{\circ} \mathrm{C}$, it was found to be more thermally stable than the u-GNP above this temperature. All composite samples exhibited strong thermal stability, as no significant mass loss was observed up to $382-395^{\circ} \mathrm{C}$. The XRD diffractograms of all the composites showed that the materials were amorphous. The PGMA-GNP composites displayed more advanced mechanical properties than those of
u-GNP. The enhancements indicate that the PECVD method is a useful technique for producing GNP-reinforced polymer composites with excellent mechanical properties. The electrical percolation threshold of the nanocomposites was determined to be approximately $0.1 \mathrm{wt} \%$ filler loading, and the GNPs created an effective electrical conductivity improvement in the epoxy. All the composites had a hydrophobic surface. PGMA increased the hydrophobicity of the composites, causing a decrease in water sorption. The addition of graphene nanosheets to epoxy effectively improved the corrosion resistance of the epoxy composites in high salinity, basic, and acidic environments. The epoxy composite containing $1.5 \%$ PGMA-GNP by weight showed the best anticorrosion performance as a coating.

\section{Acknowledgements}

We express our thanks to the Selcuk University Scientific Research Foundation, which has financed Project 17101014, a part of which is presented in this study.

\section{References}

[1] Alipour A., Giffney T., Lin R., Jayaraman K.: Effects of matrix viscosity on morphological and rheological properties and the electrical percolation threshold in graphene/epoxy nanocomposites. Express Polymer Letters, 15, 541-553 (2021).

https://doi.org/10.3144/expresspolymlett.2021.46 
[2] Xu Y., Gao D., Dong Q., Li M., Liu A., Wang X., Wang S., Liu Q.: Anticorrosive behavior of epoxy coating modified with hydrophobic nano-silica on phosphatized carbon steel. Progress in Organic Coatings, 151, 106051 (2021).

https://doi.org/10.1016/j.porgcoat.2020.106051

[3] Kocaman S., Gursoy M., Karaman M., Ahmetli G.: Synthesis and plasma surface functionalization of carbon nanotubes for using in advanced epoxy-based nanocomposites. Surface and Coatings Technology, 399, 126144 (2020). https://doi.org/10.1016/j.surfcoat.2020.126144

[4] Ganjaee Sari M., Ramezanzadeh B., Pakdel A. S., Shahbazi M.: A physico-mechanical investigation of a novel hyperbranched polymer-modified clay/epoxy nanocomposite coating. Progress in Organic Coatings, 99, 263-273 (2016).

https://doi.org/10.1016/j.porgcoat.2016.06.003

[5] Hu C., Le A. T., Pung S. Y., Stevens L., Neate N., Hou X., Grant D., Xu F.: Efficient dye-removal via Ni-decorated graphene oxide-carbon nanotube nanocomposites. Materials Chemistry and Physics, 260, 124117 (2021). https://doi.org/10.1016/j.matchemphys.2020.124117

[6] Atif R., Shyha I., Inam F.: Mechanical, thermal, and electrical properties of graphene-epoxy nanocomposites - A review. Polymers, 8, 281 (2016). https://doi.org/10.3390/polym8080281

[7] Khan N. I., Halder S., Talukdar N., Das S., Goyat M. S.: Surface oxidized/silanized graphite nanoplatelets for reinforcing an epoxy matrix. Materials Chemistry and Physics, 258, 123851 (2021).

https://doi.org/10.1016/j.matchemphys.2020.123851

[8] Morales-Zamudio L., Lozano T., Caballero-Briones F., Zamudio M. A. M., Angeles-San Martin M. E., de LiraGomez P., Martinez-Colunga G., Rodriguez-Gonzalez F., Neira G., Sanchez-Valdes S.: Structure and mechanical properties of graphene oxide-reinforced polycarbonate. Materials Chemistry and Physics, 261, 124180 (2021). https://doi.org/10.1016/j.matchemphys.2020.124180

[9] Tang L-C., Wan Y-J., Yan D., Pei Y-B., Zhao L., Li Y-B., Wu L-B., Jiang J-X., Lai G-Q.: The effect of graphene dispersion on the mechanical properties of graphene/epoxy composites. Carbon, 60, 16-27 (2013). https://doi.org/10.1016/j.carbon.2013.03.050

[10] Ma P-C., Siddiqui N. A., Marom G., Kim J-K.: Dispersion and functionalization of carbon nanotubes for polymer-based nanocomposites: A review. Composites Part A: Applied Science and Manufacturing, 41, 1345-1367 (2010). https://doi.org/10.1016/j.compositesa.2010.07.003

[11] Vallés C., Papageorgiou D. G., Lin F., Li Z., Spencer B. F., Young R. J., Kinloch I. A.: PMMA-grafted graphene nanoplatelets to reinforce the mechanical and thermal properties of PMMA composites. Carbon, 157, 750-760 (2020).

https://doi.org/10.1016/j.carbon.2019.10.075
[12] Butmee P., Tumcharern G., Saejueng P., Stankovic D., Ortner A., Jitcharoen J., Kalcher K., Samphao A.: A direct and sensitive electrochemical sensing platform based on ionic liquid functionalized graphene nanoplatelets for the detection of bisphenol A. Journal of Electroanalytical Chemistry, 833, 370-379 (2019).

https://doi.org/10.1016/j.jelechem.2018.12.014

[13] Ahmadi-Moghadam B., Sharafimasooleh M., Shadlou S., Taheri F.: Effect of functionalization of graphene nanoplatelets on the mechanical response of graphene/ epoxy composites. Materials and Design, 66, 142-149 (2015).

https://doi.org/10.1016/j.matdes.2014.10.047

[14] Singh A., Kumar D.: Effect of functionalization on the elastic behavior of graphene nanoplatelet-PE nanocomposites with interface consideration using a multiscale approach. Mechanics of Materials, 132, 18-30 (2019). https://doi.org/10.1016/j.mechmat.2019.02.008

[15] Chen J., Zhang J., Hu M., Zheng Z., Wang K., Li X.: Preparation of Ni/graphene hydrophobic composite coating with micro-nano binary structure by poly-dopamine modification. Surface and Coatings Technology, 353, 1-7 (2018). https://doi.org/10.1016/j.surfcoat.2018.08.073

[16] Aussawasathien D., Hrimchum K.: Carboxylic-plasmatreated nanofiller hybrids in carbon fiber reinforced epoxy composites: Dispersion and synergetic effects. Express Polymer Letters, 15, 262-273 (2021). https://doi.org/10.3144/expresspolymlett.2021.23

[17] Enrique-Jimenez P., Quiles-Díaz S., Salavagione H. J., Wesner D., Schönherr H., González-Casablanca J., García-Quismondo R., Martínez G., Gómez-Fatou M. A., Ania F., Flores A.: Control of the structure and properties of SEBS nanocomposites via chemical modification of graphene with polymer brushes. European Polymer Journal, 97, 1-13 (2017).

https://doi.org/10.1016/j.eurpolymj.2017.09.047

[18] Eskandari P., Abousalman-Rezvani Z., RoghaniMamaqani H., Salami-Kalajahi M., Mardani H.: Polymer grafting on graphene layers by controlled radical polymerization. Advances in Colloid and Interface Science, 273, 102021 (2019).

https://doi.org/10.1016/j.cis.2019.102021

[19] Quiles-Díaz S., Enrique-Jimenez P., Papageorgiou D. G., Ania F., Flores A., Kinloch I. A., Gómez-Fatou M. A., Young R. J., Salavagione H. J.: Influence of the chemical functionalization of graphene on the properties of polypropylene-based nanocomposites. Composites Part A: Applied Science and Manufacturing, 100, 31-39 (2017).

https://doi.org/10.1016/j.compositesa.2017.04.019

[20] Kocaman S.: Synthesis and cationic dye biosorption properties of a novel low-cost adsorbent: Coconut waste modified with acrylic and polyacrylic acids. International Journal of Phytoremediation, 22, 551-566 (2020).

https://doi.org/10.1080/15226514.2020.1741509 
[21] Kara A. S., Kocaman S., Karaman M., Gursoy M., Ahmetli G.: Preparation of epoxy composites using perlite as filler. in 'Proceeding of International Conference on Engineering Technologies (ICENTE'17)' 144, Konya, Turkey (2017).

[22] Chandrasekaran S., Seidel C., Schulte K.: Preparation and characterization of graphite nano-platelet (GNP)/ epoxy nano-composite: Mechanical, electrical and thermal properties. European Polymer Journal, 49, 38783888 (2013).

https://doi.org/10.1016/j.eurpolymj.2013.10.008

[23] Chatterjee S., Nafezarefi F., Tai N. H., Schlagenhauf L., Nüesch F. A., Chu B. T. T.: Size and synergy effects of nanofiller hybrids including graphene nanoplatelets and carbon nanotubes in mechanical properties of epoxy composites. Carbon, 50, 5380-5386 (2012). https://doi.org/10.1016/j.carbon.2012.07.021

[24] Naeem M., Kuan H-C., Michelmore A., Meng Q., Qui A., Aakyiir M., Losic D., Zhu S., Ma J.: A new method for preparation of functionalized graphene and its epoxy nanocomposites. Composites Part B: Engineering, 196, 108096 (2020).

https://doi.org/10.1016/j.compositesb.2020.108096

[25] Ding J., ur Rahman O., Peng W., Dou H., Yu H.: A novel hydroxyl epoxy phosphate monomer enhancing the anticorrosive performance of waterborne graphene/ epoxy coatings. Applied Surface Science, 427, 981-991 (2018). https://doi.org/10.1016/j.apsusc.2017.08.224

[26] Liang J. Z., Wang J. Z., Tsui G. C. P., Tang C. Y.: Thermal properties and thermal stability of polypropylene composites filled with graphene nanoplatelets. Journal of Thermoplastic Composite Materials, 31, 246-264 (2018).

https://doi.org/10.1177/0892705717697777

[27] Kocaman S., Ahmetli G.: Effects of various methods of chemical modification of lignocellulose hazelnut shell waste on a newly synthesized bio-based epoxy composite. Journal of Polymers and the Environment, 28, 11901203 (2020). https://doi.org/10.1007/s10924-020-01675-1

[28] Yel E., Aslanov T., Sogancioglu M., Kocaman S., Ahmetli G.: Production of biocomposites using chars obtained by co-pyrolysis of olive pomace with plastic wastes. International Journal of Bioengineering and Life Sciences, 10, 231-234 (2016).

https://doi.org/10.5281/zenodo.1123841

[29] Zhu L., Zhao X., Li Y., Yu X., Li C., Zhang Q.: Highquality production of graphene by liquid-phase exfoliation of expanded graphite. Materials Chemistry and Physics, 137, 984-990 (2013). https://doi.org/10.1016/j.matchemphys.2012.11.012

[30] Wu C., Cheng Q., Wu K., Wu G., Li Q.: Graphene prepared by one-pot solvent exfoliation as a highly sensitive platform for electrochemical sensing. Analytica Chimica Acta, 825, 26-33 (2014).

https://doi.org/10.1016/j.aca.2014.03.036
[31] Liu M., Zhang X., Wu W., Liu T., Liu Y., Guo B., Zhang R.: One-step chemical exfoliation of graphite to $\sim 100 \%$ few-layer graphene with high quality and large size at ambient temperature. Chemical Engineering Journal, 355, 181-185 (2019).

https://doi.org/10.1016/j.cej.2018.08.146

[32] Akhavan O., Ghaderi E., Hashemi E., Rahighi R.: Ultrasensitive detection of leukemia by graphene. Nanoscale, 6, 14810-14819 (2014).

https://doi.org/10.1039/C4NR04589K

[33] Zou X. P., Kang E. T., Neoh K. G., Cui C. G., Lim T. B.: Surface modification of poly(tetrafluoroethylene) films by plasma polymerization of glycidyl methacrylate for adhesion enhancement with evaporated copper. Polymer, 42, 6409-6418 (2001).

https://doi.org/10.1016/S0032-3861(01)00113-6

[34] Goswami P. K., Kashyap M., Das P. P., Saikia P. J., Handique J. G.: Poly(glycidyl methacrylate-co-octadecyl methacrylate) particles by dispersion radical copolymerization. Journal of Dispersion Science and Technology, 41, 1768-1776 (2020).

https://doi.org/10.1080/01932691.2019.1635026

[35] Nan H. Y., Ni Z. H., Wang J., Zafar Z., Shi Z. X., Wang Y. Y.: The thermal stability of graphene in air investigated by Raman spectroscopy. Journal of Raman Spectroscopy, 44, 1018-1021 (2013).

https://doi.org/10.1002/jrs.4312

[36] Ozlem-Gundogdu S., Gurel E. A., Hacaloglu J.: Pyrolysis of of poly(methy methacrylate) copolymers. Journal of Analytical and Applied Pyrolysis, 113, 529-538 (2015). https://doi.org/10.1016/j.jaap.2015.03.015

[37] Hu Y-H., Chen C-Y., Wang C-C.: Thermal degradation kinetics of poly(n-butyl acrylate) initiated by lactams and thiols. Polymer Degradation and Stability, 84, 505514 (2004).

https://doi.org/10.1016/j.polymdegradstab.2004.01.009

[38] Saha M., Tambe P., Pal S.: Thermodynamic approach to enhance the dispersion of graphene in epoxy matrix and its effect on mechanical and thermal properties of epoxy nanocomposites. Composite Interfaces, 23, 255272 (2016).

https://doi.org/10.1080/09276440.2016.1136515

[39] Soydal U., Kocaman S., Marti M. E., Ahmetli G.: Study on the reuse of marble and andesite wastes in epoxybased composites. Polymer Composites, 39, 3081-3091 (2018). https://doi.org/10.1002/pc.24313

[40] $\mathrm{Hu}$ Z., Song C., Shao Q., Li J., Huang Y.: One-step functionalization of graphene by cycloaddition of diarylcarbene and its application as reinforcement in epoxy composites. Composites Science and Technology, 135, 21-27 (2016).

https://doi.org/10.1016/j.compscitech.2016.09.008

[41] Xiang S., Wang X., Gupta M., Wu K., Hu X., Zheng M.: Graphene nanoplatelets induced heterogeneous bimodal structural magnesium matrix composites with enhanced mechanical properties. Scientific Reports, 6, 38824 (2016).

https://doi.org/10.1038/srep38824 
[42] Park S., Kim D. S.: Preparation and physical properties of an epoxy nanocomposite with amine-functionalized graphenes. Polymer Engineering and Science, 54, 985991 (2014)

https://doi.org/10.1002/pen.23368

[43] Covarrubias-Gordillo C. A., Soriano-Corral F., ÁvilaOrta C. A., Cruz-Delgado V. J., Neira-Velázquez M. G., Hernández-Hernández E., Hernández-Gámez J. F., de León-Martínez P. A.: Surface modification of carbon nanofibers and graphene platelets mixtures by plasma polymerization of propylene. Journal of Nanomaterials, 2017, 4875319 (2017). https://doi.org/10.1155/2017/4875319

[44] Lan D., Xiong L., Wanyan H., Yuan Y., Fan Q., Zeng X., Chen Y., Cao Z.: Poly(glycidyl methacrylate) grafted to carbon fiber surface by RAFT polymerization for enhancing interface adhesion and mechanical properties of carbon fiber/epoxy composites. Polymers and Polymer Composites, 25, 113-118 (2017). https://doi.org/10.1177/096739111702500115

[45] Li S., Gu A., Liang G., Yuan L., Xue J.: A facile and green preparation of poly(glycidyl methacrylate) coated aramide fibers. Journal of Materials Chemistry, 22, 8960-8968 (2012). https://doi.org/10.1039/C2JM16602J

[46] Zhao H., Yang C., Li N., Yin J., Feng Y., Liu Y., Li J., Li Y., Yue D., Zhu C., Liu X.: Electrical and mechanical properties of polyimide composite films reinforced by ultralong titanate nanotubes. Surface and Coatings Technology, 360, 13-19 (2019).

https://doi.org/10.1016/j.surfcoat.2019.01.013

[47] Lin Y-T., Don T-M., Wong C-J., Meng F-C., Lin Y-J., Lee S-Y., Lee C-F., Chiu W-Y.: Improvement of mechanical properties and anticorrosion performance of epoxy coatings by the introduction of polyaniline/ graphene composite. Surface and Coatings Technology, 374, 1128-1138 (2019).

https://doi.org/10.1016/j.surfcoat.2018.01.050

[48] Jun Y-S., Um J. G., Jiang G., Yu A.: A study on the effects of graphene nano-platelets ( $\mathrm{GnPs}$ ) sheet sizes from a few to hundred microns on the thermal, mechanical, and electrical properties of polypropylene (PP)/GnPs composites. Express Polymer Letters, 12, 885-897 (2018).

https://doi.org/10.3144/expresspolymlett.2018.76

[49] Marsden A. J., Papageorgiou D. G., Vallés C., Liscio A., Palermo V., Bissett M. A., Young R. J., Kinloch I. A.: Electrical percolation in graphene-polymer composites. 2D Materials, 5, 032003 (2018).

https://doi.org/10.1088/2053-1583/aac055

[50] Kocaman S.: Chemical modification of apricot kernel shell waste and its effect on phenolic novolac epoxy composites. Journal of Applied Polymer Science, 137, 49267 (2020).

https://doi.org/10.1002/app.49267

[51] Soydal U., Marti M. E., Kocaman S., Ahmetli G.: Evaluation of sugar mill lime waste in biobased epoxy composites. Polymer Composites, 39, 924-935 (2018). https://doi.org/10.1002/pc.24019
[52] Ibrahim A., Ridha S., Amer A., Shahari R., Ganat T. Influence of degree of dispersion of noncovalent functionalized graphene nanoplatelets on rheological behaviour of aqueous drilling fluids. International Journal of Chemical Engineering, 2019, 8107168 (2019).

https://doi.org/10.1155/2019/8107168

[53] Watt E., Abdelwahab M. A., Snowdon M. R., Mohanty A. K., Khalil H., Misra M.: Hybrid biocomposites from polypropylene, sustainable biocarbon and graphene nanoplatelets. Scientific Reports, 10, 10714 (2020).

https://doi.org/10.1038/s41598-020-66855-4

[54] Huang W., Zhou Y., Yan D.: Direct synthesis of amphiphilic block copolymers from glycidyl methacrylate and poly(ethylene glycol) by cationic ring-opening polymerization and supramolecular self-assembly thereof. Journal of Polymer Science Part A: Polymer Chemistry, 43, 2038-2047 (2005). https://doi.org/10.1002/pola.20688

[55] Pinto A. M., Martins J., Moreira J. A., Mendes A. M., Magalhães F. D.: Dispersion of graphene nanoplatelets in poly(vinyl acetate) latex and effect on adhesive bond strength. Polymer International, 62, 928-935 (2013). https://doi.org/10.1002/pi.4379

[56] Choi W., Lee J-W.: Graphene: Synthesis and applications. CRC Press, New York (2020).

https://doi.org/10.1201/b11259

[57] Huang S., Kong G., Yang B., Zhang S., Che C.: Effects of graphene on the corrosion evolution of zinc particles in waterborne epoxy zinc-containing coatings. Progress in Organic Coatings, 140, 105531 (2020).

https://doi.org/10.1016/j.porgcoat.2019.105531

[58] Zhang Z., Zhang W., Li D., Sun Y., Wang Z., Hou C., Chen L., Cao Y., Liu Y.: Mechanical and anticorrosive properties of graphene/epoxy resin composites coating prepared by in-situ method. International Journal of Molecular Sciences, 16, 2239-2251 (2015). https://doi.org/10.3390/ijms16012239

[59] Zhu L., Feng C., Cao Y.: Corrosion behavior of epoxy composite coatings reinforced with reduced graphene oxide nanosheets in the high salinity environments. Applied Surface Science, 493, 889-896 (2019).

https://doi.org/10.1016/j.apsusc.2019.06.271

[60] Yan H., Li J., Zhang M., Zhao Y., Feng Y., Zhang Y.: Enhanced corrosion resistance and adhesion of epoxy coating by two-dimensional graphite-like g- $\mathrm{C}_{3} \mathrm{~N}_{4}$ nanosheets. Journal of Colloid and Interface Science, 579, 152-161 (2020). https://doi.org/10.1016/j.jcis.2020.06.027

[61] Kabeb S., Hassan A., Mohamad Z., Sharer Z., Mokhtar M., Ahmad F.: Effect of graphene nanoplatelets on flame retardancy and corrosion resistance of epoxy nanocomposite coating. Malaysian Journal of Fundamental and Applied Sciences, 15, 543-547 (2019).

https://doi.org/10.11113/mjfas.v15n4.1399

[62] Monetta T., Acquesta A., Bellucci F.: Graphene/epoxy coating as multifunctional material for aircraft structures. Aerospace, 2, 423-434 (2015).

https://doi.org/10.3390/aerospace2030423 